\title{
High levels of truncated RHAMM cooperate with dysfunctional p53 to accelerate the progression of pancreatic cancer
}

Jennifer Feng ${ }^{1, \#}$, Anthony Lin ${ }^{1, \#}$, Xiang Chen ${ }^{1}$, Dunrui Wang ${ }^{2}$, Megan Wong ${ }^{1}$, George Zhang ${ }^{1}$, Joseph $\mathrm{Na}^{1}$, Tiantian Zhang ${ }^{1}$, Zhengming $\mathrm{Chen}^{3}$, Yao-Tseng Chen ${ }^{1}$, Yi-Chieh Nancy Du ${ }^{1}$

${ }^{1}$ Department of Pathology and Laboratory Medicine, Weill Cornell Medicine, New York, NY 10065

${ }^{2}$ Laboratory of Cellular Oncology, National Cancer Institute, National Institutes of Health, Bethesda, MD 20892

${ }^{3}$ Division of Biostatistics and Epidemiology, Department of Population Health Sciences, Weill Cornell Medicine, New York, NY 10065

\#: equal contribution.

Corresponding author: Yi-Chieh Nancy Du, Department of Pathology and Laboratory Medicine, Weill Cornell Medicine, New York, NY 10065. Phone: 212-746-7312; Fax: 212-746-4483; Email:nad2012@med.cornell.edu

\section{Running title: $H_{M M R^{\Delta e x o n 8-16}}$ cooperates with dysfunctional p53 in pancreatic cancer}




\begin{abstract}
Pancreatic cancer has the lowest survival rate in all types of cancer. Pancreatic cancer patients are often diagnosed at advanced stages. A better therapeutic development for this devastating disease is urgently needed. Receptor for hyaluronan-mediated motility (RHAMM), not expressed in adult pancreas, has been suggested as a prognostic factor and a potential therapeutic target for pancreatic ductal adenocarcinoma (PDAC) and pancreatic neuroendocrine tumor (PNET). In this study, we initially sought to determine whether genetic deletion of $R H A M M$ would slow down pancreatic cancer progression using Rhamm$^{-/-}$mice. However, we found that Rhamm $^{-/}$mice expressed a truncated HMMR ${ }^{\Delta \text { exon8-16 }}$ protein at higher abundance levels than wild-type RHAMM. While HMMR ${ }^{\Delta \text { exon8-16 }}$ did not enable malignant progression of pancreatic intraepithelial neoplasia in $p 48-C r e ; L S L-K R A S^{G 12 D}$ mice, it accelerated the formation of invasive PDAC and shortened the survival of $p 48-C r e$; $L S L-K R A S^{G 12 D}$ mice with heterozygous p53 knockout. $\operatorname{Kras}^{G 12 D}$ PDAC mice with homozygous p53 knockout mice died around 10 weeks, and the effect of $\mathrm{HMMR}^{\Delta \text { exon8-16 }}$ was not apparent in these mice with short-life span. In addition, HMMR ${ }^{\Delta \text { exon8-16 }}$ shortened the survival of PNET-bearing RIP-Tag mice, which had inactivated p53. In our analysis of TCGA dataset, pancreatic cancer patients with mutant TP53 or loss of one copy of TP53 had higher RHAMM expression, which, combined, predicted worse outcomes. Taken together, by collaborating with dysfunctional p53, high levels of HMMR ${ }^{\Delta \text { exon8- }}$ 16 that lacks the centrosome targeting domain and degrons for interaction with the AnaphasePromoting Complex (APC) accelerated pancreatic cancer progression.
\end{abstract}




\begin{abstract}
Abbreviations
APC, anaphase-promoting complex; CN: copy number; CNV: copy number variation; ES, embryonic stem; HMMR ${ }^{\Delta \text { exon8-16}, ~ N-t e r m i n a l ~ R H A M M ~ l a c k i n g ~ e x o n s ~} 8 \sim 16$; MU, mutation; OS: overall survival; $p 53^{\text {lox/+ }}$, heterozygous p53 loss; $p 53^{\text {lox/lox }}$, homozygous-null p53; PanIN, pancreatic intraepithelial neoplasia; PDAC, pancreatic ductal adenocarcinoma; PNET, pancreatic neuroendocrine tumor; PCR, polymerase chain reaction; RHAMM or HMMR, receptor for hyaluronic acid-mediated motility; $\mathrm{RHAMM}^{\mathrm{B}}$, receptor for hyaluronan-mediated motility isoform B; Rb, retinoblastoma; RIP, rat insulin promoter; Tag, T antigen; TCGA, The Cancer Genome Atlas; WT, wild-type.
\end{abstract}




\section{Introduction}

Pancreatic cancer is the leading cause of cancer-related death. In contrast to the steady increase in survival observed for most cancer types, advances have been slow for pancreatic cancer, which is typically diagnosed at an advanced stage [1]. About $90 \%$ of all malignant pancreatic tissues are pancreatic ductal adenocarcinoma (PDAC) with a five-year survival rate of $<10 \%$ [2]. $K R A S, C D K N 2 A, T P 53$, and SMAD4 are the four frequently mutated genes that characterize PDAC [3]. Activating $K R A S$ mutations are present in more than $99 \%$ of pancreatic intraepithelial neoplasia (PanIN) and over 90\% of PDAC, and has been shown to be an initiating event of PDAC using genetically engineered mouse models [4]. Studies from mouse models of PDAC further demonstrated that loss of functional p53 cooperates with mutant KRAS to cause rapid PDAC progression and metastasis [5].

Pancreatic neuroendocrine tumor (PNET) is the second most common malignancy of the pancreas. The incidence of PNET is increasing and PNET presents with a wide variety of clinical manifestations and unfavorable survival rates [6]. Unlike PDAC, the major molecular driver for PNETs is not well-understood. Recent molecular characterization of PNETs reveals alterations in pathways/genes such as mTOR pathway, cyclin D1/Cdk4/retinoblastoma (Rb), TP53, MEN1, DAXX, ATRX, UCHL 1, RHAMM, and microRNAs [7-9]. In the RIP-Tag mouse model of PNET, the rat insulin promoter (RIP) drives the expression of SV40 T antigen (Tag), providing the driving force for tumor initiation by inhibiting the activities of tumor suppressors, p53 and Rb [10]. Preclinical trials in the RIP-Tag mice have predicted that sunitinib and everolimus would be effective in treating human PNETs [11-13]. However, sunitinib and everolimus only extend 
the median patient survival by roughly 6 months, and all patients eventually develop resistance to both drugs $[14,15]$.

Receptor for hyaluronic acid-mediated motility (RHAMM or HMMR) was identified as a receptor of hyaluronan [16], and its expression peaks at G2/M [17, 18]. Studies have shown that RHAMM plays an important role in cell motility [19]. Human RHAMM encodes 18 exons and alternative splicing yields four isoforms [20]. Of the four isoforms (RHAMMv1-4), we have shown mRNA expression levels of RHAMMv3, also known as $R H A M M^{B}$, to be the most prominent in human PDAC, PNET, and liver metastases of PNET [21]. Using the RIP-Tag; RIPtva mouse model of PNET and cell line xenograft mouse models, we have discovered RHAMM ${ }^{\mathrm{B}}$ as the first protein that is able to promote PNET metastasis to the liver [21, 22], and we have also found $R H A M M^{B}$ expression to correlate with poor survival in PDAC patients [21]. Most normal human tissues, including pancreas, do not express RHAMM [17, 21], and the differential RHAMM expression in normal tissues and pancreatic cancer may thus provide novel therapeutic possibilities by targeting RHAMM. To investigate whether RHAMM is a potential therapeutic target in pancreatic cancer, we set out to determine the effects of RHAMM deletion on the progression and survival of PDAC and PNET in mouse models using Rhamm $^{-/}$mice [23]. However, after analyzing RHAMM mRNA and protein expression in Rhamm-/- mice, we unexpectedly discovered that a truncated $\mathrm{HMMR}^{\Delta \text { exon8-16 }}$ protein was expressed in Rhamm $^{-/}$mice and was more abundant than the full-length protein in RHAMM wide-type (WT) mice. Based on these findings, we propose to re-name $\mathrm{Rhamm}^{-/-}$mice as $H M M R^{4 \text { exon8-16/4exon8-16 }}$ mice. In this study, we investigated the effects of the $\mathrm{HMMR}^{\Delta \text { exon8-16 }}$ protein on tumor progression and survival of PDAC and PNET in mouse models. 


\section{Results}

\section{Detection of HMMR ${ }^{\Delta \text { exon8-16 }}$ protein in Rhamm $^{-/-}$mice}

Mouse RHAMM/HMMR has 18 exons (NM_013552.2). The Rhamm$^{-/}$mouse strain was previously generated by deleting exons $8 \sim 16$ of the $H M M R$ gene through homologous recombination in embryonic stem (ES) cells [23]. It was reported that no HMMR protein was detected in the spleen lysate of Rhamm $^{-/}$mice using RHAMM polyclonal antibody in Western blot analysis [23]. However, because the polyclonal antibody was generated against recombinant RHAMM protein [23] and the specific immunogenic epitope(s) are unknown, we decided to investigate whether any truncated RHAMM protein was expressed in Rhamm $^{-/}$mice using a RHAMM-specific monoclonal antibody against the N-terminus (clone EPR4054). The immunogen for this clone EPR4054 was the first 50 amino acids of human RHAMM, and the antibody cross-reacted with mouse RHAMM. Full-length WT mouse RHAMM encodes 794 amino acids with a predicted molecular weight of $\sim 92 \mathrm{kDa}$. We have previously reported that the testis has the most abundant RHAMM proteins among all adult human tissues [17], so we predicted that RHAMM would also be highly expressed in mouse testis and therefore the testis is a better tissue than spleen to evaluate whether a truncated RHAMM protein was expressed. To verify that exons $8 \sim 16$ were deleted in the $\mathrm{Rhamm}^{-/}$mice, we isolated mRNA from the testis of Rhamm $^{-/}$mice $(\mathrm{n}=3)$, made cDNA, amplified RHAMM fragments by polymerase chain reaction (PCR), and performed DNA sequencing. Our analysis confirmed a fusion of exon 7 and exon 17, which resulted in a stop codon in exon 17 and would yield a truncated RHAMM of 239 amino acids with a predicted molecular weight of $\sim 27 \mathrm{kDa}$ (Figure 1A). In addition, we found an adenine to cytosine missense mutation at nucleotide position 290 , which changed the amino acid 
from lysine to threonine (residue 71) (Figure 1A and Figure 2). Protein lysates and histological sections from testes of WT mice and $\mathrm{Rhamm}^{-/}$mice were then evaluated for the expression of RHAMM proteins. Western blot analysis using EPR4054 antibody detected full-length RHAMM protein $(\sim 92 \mathrm{kDa})$ in WT mouse testes and truncated RHAMM protein $(\sim 27 \mathrm{kDa})$ in $R h a m m^{-/-}$ mouse testes (Figure 1B). Immunohistochemical staining using EPR4054 antibody also revealed RHAMM protein in Rhamm $^{-/}$mouse testes (Figure 1C). Both Western blot and immunohistochemical analyses showed that the truncated RHAMM protein $\left(\mathrm{HMMR}^{\Delta \mathrm{exon8} 8 \mathrm{-16}}\right)$ was highly expressed in $\mathrm{Rhamm}^{-/}$mice, at levels more abundant than WT RHAMM protein in the control WT mice. Therefore, we renamed this mouse strain from Rhamm $^{-/-}$to $H M M R^{\Delta e x o n 8-}$ 16/4 exon8-16.

\section{$H M M R^{\Delta e x o n 8-16 / 4 \text { exons-16 }}$ mice have normal pancreas development}

Consistent with the previous report [23], we found no embryonic lethality for $H M M R^{4 \text { exons-16/4 }}$ ${ }^{\text {exon8-16 }}$ mice. The appearance of $H M M R^{\Delta e x o n 8-16 / 4 \text { exon8-16 }}$ mice was normal throughout their lifespan and live longer than 1 year without any spontaneous tumorigenesis (data not shown). To determine whether the truncated RHAMM protein $\left(\mathrm{HMMR}^{\Delta \text { exon8-16}}\right)$ causes any abnormality in pancreatic development, the pancreas from adult $H M M R^{\Delta e x o n 8-16 / 4 \text { exon8-16 }}$ was examined and no histologic abnormality was identified (Figure 3A).

\section{$H M M R^{\Delta e x o n 8-16}$ did not alter the course of PanIN formation in $p 48-C r e ; L S L-K R A S^{G 12 D}$ mice}

It has been shown that the expression of mutant $K R A S^{G 12 D}$ from the endogenous locus in the mouse pancreas leads to the development of premalignant ductal lesions, PanINs, in Pdxl-Cre; $L S L-K R A S^{G 12 D}$ mice and $p 48-C r e ; L S L-K R A S^{G 12 D}$ mice [4]. Subsequent studies revealed that $\mathrm{p} 53$ 
constrains the progression of PanIN to advanced PDAC $[5,24]$. Pdx1-Cre; LSL-KRAS G12D mice harboring heterozygous p53 loss or homozygous-null p53 developed PDAC with an average latency of 21.8 weeks or 6.2 weeks, respectively [5]. Because the expression of the Cre recombinase under $\mathrm{p} 48$ promoter is restricted to mouse pancreas compared to that under the Pdx 1 promoter [3], we decided to use $p 48$-Cre instead of Pdx1-Cre to target mutant Kras ${ }^{\mathrm{G} 12 \mathrm{D}}$ expression in the pancreas in this study. To determine the effect of N-terminal RHAMM $\left(\mathrm{HMMMR}^{\Delta \mathrm{exon8-16}}\right)$ on the initiation and the progression of PanINs and pancreatic ductal adenocarcinomas (PDAC), we crossed $H M M R^{\Delta e x o n 8-16 / \Delta \text { exon8-16 }}$ to $p 48-C r e ; L S L-K R A S^{G 12 D}$ mice with WT p53 (Group A), heterozygous p53 loss (p53 lox/+ , Group B), or homozygous-null p53 (p53 lox/lox , Group C) (Table 1). Within each group (A, B, and C), we evaluated the impact of WT HMMR (A0, B0, and C0), one copy of $H M M R^{\Delta \text { exon8-16 }}\left(H M M R^{\Delta \text { exon8-16/WT }}\right.$ A1, B1, and C1), and

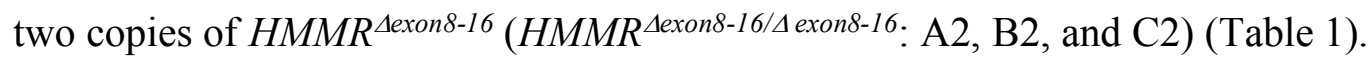

As expected, our cohort of $p 48-C r e ; L S L-K R A S^{G 12 D}$ mice (A0) developed PanINs (Figure 3B). The majority of the A group mice lived longer than 40 weeks of age (Figure 3E). We found no significant survival difference among A0, A1, and A2 after following them up to 1 year (Figure 3E, Log-rank test, A0: 32 mice, A1: 45 mice, and A2: 35 mice). Similar results were obtained from Cox regression (data not shown). Mice in A0, A1, and A2 at the end point (1 year of age) all developed PanINs, but no invasive PDAC (Figure 3B-D). Our data suggest that N-terminal RHAMM protein $\left(\mathrm{HMMR}^{\Delta \text { exon8-16}}\right)$ cannot promote the progression of PanINs initiated by $K R A S^{G 12 D}$ to PDAC. 


\section{$H M M R^{\Delta e x o n 8-16}$ shortened the survival and accelerated PDAC formation in $p 48$-Cre; $L S L$ - $K R A S^{G 12 D} ; p 53^{l o x /+}$ mice}

We established a cohort of B group, p48-Cre; LSL-KRAS $S^{G 12 D}$ mice with heterozygous p53 loss $\left(p 53^{\text {lox/+ }}\right)$ and different copy numbers of $H M M R^{\text {\exon8-16 }}$ (B0, B1, and B2). Mice in the B group lived less than a year, and all mice in these three subgroups developed advanced PDAC at death or when they were sick (Figure 4 and data not shown). Having either one copy or two copies of $H M M R^{4 e x o n 8-16}$ significantly shortened the survival of $p 48-C r e ; L S L-K R A S^{G 12 D} ; p 53^{\text {lox/+ }}$ mice (Figure 4A, Log-rank test, B0: 86 mice, B1: 57 mice, and B2: 36 mice). The median survival ages for B0, B1, and B2 were 22.93 weeks, 17.5 weeks, and 15.14 weeks, respectively (Table 1). Cox regression analysis showed that B1 is $164 \%$ more likely to die at any time point than B0 $(P$ $<0.0001)$ and B2 is $234 \%$ more likely to die than B0 $(P<0.0001)$. At the terminal stage of each subgroup, there was no significant different PDAC histology found between $p 48$-Cre; LSL$K R A S^{G 12 D} ; p 53^{l o x /+}$ mice with either one copy or two copies of $H M M R^{\text {Aexon8-16 }}$ (Figure 4B-G, and data not shown). However, direct invasion of PDAC into peripancreatic lymph nodes and metastasis to liver were observed in mice with $H M M R^{\Delta e x o n 8-16}$ (Figure 4F and 4G).

To investigate why $p 48-C r e ; L S L-K R A S^{G 12 D} ; p 53^{\text {lox/+ }} ; H M M R^{4 e x o n 8-16 / W T}(\mathrm{~B} 1)$ died earlier than p48-Cre; LSL-KRAS ${ }^{G 12 D} ; p 53^{l o x /+}$ (B0), we sacrificed a cohort of B0 and B1 mice at the age of 15 weeks ( $\mathrm{n}=3$ per group). We found that whereas B0 mice showed only PanINs and not PDAC at 15 weeks (Figure 5A and 5B), B1 mice already developed invasive PDAC (Figure 5C, 5D, and 5E). Taken together, in the presence of heterozygous p53 loss, having one copy of HMMR ${ }^{\Delta e x o n 8-}$ ${ }^{16}$ was sufficient to accelerate progression of PanINs into invasive PDAC, leading to the shortened survival in the $p 48-C r e ; L S L-K R A S^{G 12 D} ; p 53^{l o x /+}$ mice. 


\section{p48-Cre; LSL-KRAS ${ }^{G 12 D} ; p 53^{l o x / l o x}$ mice had rapid PDAC progression irrespective of $H_{M M R^{\Delta e x o n 8-16}}$ status}

We established a cohort of group C mice of $p 48-C r e ; L S L-K R A S^{G 12 D} ; p 53^{\text {lox/lox }}$. These mice were further divided into 3 subgroups $(\mathrm{C} 0, \mathrm{C} 1$, and $\mathrm{C} 2)$ based on the copy numbers of $H M M R^{4 e x o n 8-16}$. PDAC histology at the terminal stage among $\mathrm{C} 0, \mathrm{C} 1$, and $\mathrm{C} 2$ subgroups were similar. The $\mathrm{C}$ group mice developed advanced PDAC as the B group but at earlier ages (Figure 6A-C). The mice in the $\mathrm{C}$ group had very short life span (Figure 6D and Table 1, Log-rank test, C0: 67 mice, C1: 33 mice, and C2: 31 mice). The median survival ages for $\mathrm{C} 0, \mathrm{C} 1$, and $\mathrm{C} 2$ were all between 9 and 10 weeks (Table 1). There was no significant difference in survival found by log-rank test.

\section{$H M M R^{\Delta e x o n 8-16}$ reduced the survival of RIP-Tag PNET mice}

RIP-Tag mice developed insulinoma, one subtype of PNETs [10]. As a result, the RIP-Tag mice died before 18 weeks of age due to hypoglycemia. Because homozygous RIP-Tag mice develop PNET faster [25], only hemizygous RIP-Tag mice in C57BL/6 background were used here. We established a cohort of RIP-Tag mice (T group) with different copy numbers of HMMR ${ }^{\Delta e x o n 8-16}$ (T0, T1, and T2). Healthy mice have non-fasting blood glucose levels around $200 \mathrm{mg} / \mathrm{dL}$, and T group mice developed PNET with blood glucose levels lower than $50 \mathrm{mg} / \mathrm{dL}$ at the end point (data not shown). PNET histology at the terminal stage among the T subgroups were similar (Figure 7A-C). RIP-Tag; HMMR ${ }^{\text {4exon8-16/WT }}$ (T1) and RIP-Tag; HMMR $R^{\text {Lexon8-16/Aexon8-16 }}$ (T2) died earlier than RIP-Tag (T0) (Figure 7D). Similar to the log-rank test results (Figure 7D), Cox regression analysis showed borderline significant difference between T1 vs T0: T1 is $46 \%$ more likely to die than T0 $(P=0.0573)$, and significant difference between T2 vs T0: T2 is $78 \%$ more 
likely to die than T0 $(P=0.0029)$. The median survival ages for T0, T1, and T2 mice were 17.57 weeks, 16.14 weeks, and 15.5 weeks, respectively (Table 1, T0: 58 mice, T1: 48 mice, and T2: 56 mice).

\section{The association between $R H A M M$ expression levels and TP53 mutations or copy number}

\section{loss in TCGA pancreatic cancer cohort}

It was previously reported that TP53 transcriptionally downregulates RHAMM in colon carcinoma cell lines [18]. We evaluated whether the RHAMM expression is associated with TP53 mutational status and copy number loss in pancreatic cancer patients using The Cancer Genome Atlas (TCGA) dataset that includes the data with gene expression (RNA-Seq), harmonized mutation, and gene level copy number. PDAC is the major pancreatic cancer type in the dataset. TP53 mutations in this dataset include missense mutation, nonsense mutation, frame shift deletion, frame shift insertion, in-frame insertion, and splice site. We found upregulation of RHAMM in the pancreatic cancer patients with TP53 mutations (Figure $8 \mathrm{~A}, P<0.05$ ). Because TP53 can also be inactivated by copy number loss, we evaluated whether the RHAMM expression is associated with the copy number variation (CNV) of TP53. We observed that RHAMM levels were higher in patients with one TP53 copy number $(\mathrm{CN}=1)$ than in patients with 2 copy numbers (Figure 8B, $P<0.05$ ). These data suggested that WT TP53 protein possess a transcriptional repression activity for $R H A M M / H M M R$ in vivo. Then, we conducted a survival analysis using RHAMM/HMMR expression and TP53 mutational status or its CNV. We found that patients have significant different survival outcome among different TP53 status/RHAMM levels combination groups. Patients who have mutant TP53/high $R H A M M$ had shortest survival among all four groups (Figure $8 \mathrm{C}$, overall log-rank $P=0.024$ ). Similarly, patients who have 
TP53 CN=1/high RHAMM had shortest survival among four groups (Figure 8D, overall log-rank $P=0.026)$.

\section{Discussion}

Pancreatic cancer is lethal and new treatment options for this devastating disease are urgently needed. We have reported that upregulation of RHAMM/HMMR in human PDAC, PNET, and many other cancer types, while RHAMM /HMMR protein is not expressed in most of the normal tissues including pancreas $[17,20,21,26,27]$. This property of RHAMM makes RHAMM blockage a very attractive therapeutic target in pancreatic cancer.

To test the above idea in pre-clinical mouse models of PDAC and PNET, we originally took advantage of an existing RHAMM deletion strain, Rhamm $^{-/}$mouse [23]. However, our molecular and histological characterization identified the expression of a truncated RHAMM $\left(\mathrm{HMMR}^{\Delta \text { exon8-16 }}\right)$ with a molecular weight of $\sim 27 \mathrm{kDa}$ in the Rhamm$^{-/-}$mice. $\mathrm{HMMR}^{\Delta \text { exon8-16 }}$ protein is more abundant than WT RHAMM/HMMR in WT mice. While HMMR ${ }^{\Delta \text { exon8-16 by }}$ itself did not promote the progression of PanINs to PDAC (Group A, p48-Cre; LSL-KRAS G12D mice), the combination of $\mathrm{HMMR}^{\Delta \text { exon8-16 }}$ and heterozygous p53 loss promote earlier onset of invasive PDAC formation (Group B, p48-Cre; LSL-KRAS $S^{G 12 D} ; p 53^{\text {lox/+ }}$ mice). The more copies

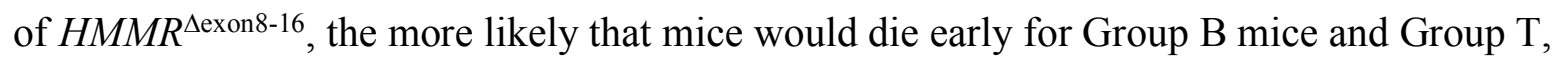
RIP-Tag PNET mice. Consistent with our findings using mouse models, pancreatic cancer patients who have mutant TP53/high $R H A M M$ or TP53 $\mathrm{CN}=1$ /high $R H A M M$ had shortest survival among different TP53 status/RHAMM levels combination groups. These data together 
supported that high levels of RHAMM/HMMR cooperated with dysfunctional p53 to accelerate the progression of pancreatic cancer in mice and in humans.

It has been shown that human RHAMM/HMMR is a G2/M protein $[17,18]$ and its C-terminus is recognized by the Anaphase-Promoting Complex (APC) for its degradation in the G1 phase [28]. Because this C-terminal homologous region is deleted in the mouse $\mathrm{HMMR}^{\Delta \text { exon8-16 }}$ protein, the $\mathrm{HMMR}^{\Delta \text { exon8-16 }}$ protein is likely not degradable by APC and this may contribute to the higher levels of the HMMR ${ }^{\Delta \text { exon8-16 }}$ protein compared to the WT protein. Besides APC, two other E3 ubiquitin ligase activities, BRCA1/BARD1 and RFWD3, have been reported to regulate RHAMM/HMMR protein levels [29-31], but the consensus amino acid sequences for BRCA1/BARD1 and RFWD3 recognition are not known.

Exons $1 \sim 4$ of RHAMM/HMMR encode a microtubule-binding region, exons $5 \sim 16$ encode the central coiled-coil region, and exons $17 \sim 18$ encode a centrosome targeting region. Full-length RHAMM has 3 putative hyaluronan-binding sites (BX7B motif) (Figure 1A). HMMR ${ }^{\Delta \text { exon8-16 }}$ protein retains one of the 3 putative hyaluronan-binding sites and exon 4 , but it loses the Cterminal centrosome targeting region because the fusion of exon 7 and exon 17 resulted in a stop codon in the middle of exon 17 . Our study indicated that the N-terminal microtubule-binding region and/or part of the central coiled-coil region are important for its oncogenic function, but the C-terminal centrosome targeting region is not. Further investigation is required to determine whether the remaining putative hyaluronan-binding motif is essential for the oncogenic function of $\mathrm{HMMR}^{\Delta \mathrm{exon8-16}}$ and whether the lysine to threonine mutation at residue 71 affects any function. Between two of the alternative splicing human RHAMM isoforms, we have previously 
demonstrated that the RHAMM ${ }^{\mathrm{B}}$, which does not have exon 4, is crucial for in vivo liver metastatic capacity of PNET, but RHAMM ${ }^{\mathrm{A}}$, which carries exon 4, cannot promote liver metastasis of PNET [21]. It remains to be investigated whether a mouse RHAMM ${ }^{\mathrm{B}}$ exists naturally or any mouse RHAMM isoform is upregulated in spontaneous mouse tumors. Because mouse $\mathrm{HMMR}^{\Delta \text { exon8-16 }}$ protein still retains exon 4 and possesses an oncogenic function, we postulate that either loss of exon 4 or loss of the C-terminal centrosome targeting region confers the oncogenic function of RHAMM/HMMR.

In addition to $H M M R^{\Delta e x o n 8-16 / \Delta e x o n 8-16}$ (previously Rhamm $^{-/}$) mouse [23], $H M M R^{m / m}$ and $H M M R^{t m 1 a / t m 1 a}$ mice have been generated $[32,33]$. A schematic of HMMR protein/gene in these mouse models can be found in the supplement figure 1 of [32]. The $H M M R^{m / m}$ mice expresses $\mathrm{HMMR}^{\Delta \text { exon11-18 }}$ protein with a molecular weight of $65 \mathrm{kDa}$ and $\mathrm{HMMR}^{\Delta \text { exon11-18 }}$ protein is also more abundant than WT proteins in mouse testis [33]. The homozygous $H M M R^{m / m}$ mice are

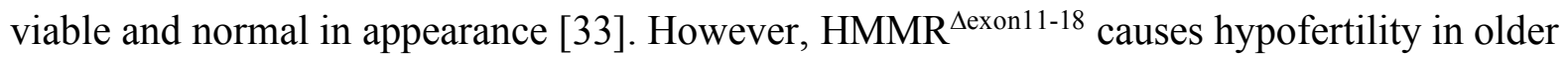
females ( $>24$ weeks old) and in male mice independently of the male's ages $[31,33]$. Because $H M M R^{m}\left(H M M R^{\operatorname{texon} 11-18}\right)$ also loses C-terminal centrosome targeting region of RHAMM encoded by exons $17 \sim 18$ and some of central coiled-coil region encoded by exons $5 \sim 16$, $H M M R^{m}\left(H M M R^{\Delta e x o n 11-18}\right)$ might promote invasive PDAC progression and reduce the survival of mice with PDAC and PNET similar to this study with $H M M R^{4 e x o n 8-16}$. A side-by-side comparison of $H M M R^{\Delta e x o n 11-18}$ and $H M M R^{\Delta e x o n 8-16 / 4 e x o n 8-16}$ for their oncogenic property would help to further dissect the functional domains of HMMR. In contrast, $H M M R^{\text {tmla/tmla }}$ mice only express the exon 1 and 2 of HMMR. HMMR ${ }^{\text {tmla/tmla }}$ mice produced litters with decreased survival, along with decreased adult body size and morphological defects in the brain, and very few mice survive to 
adulthood [32]. Thus, HMMR ${ }^{\text {tmla/tmla }}$ mice are not suitable for crossing to PDAC and PNET mouse models. A pancreas-specific knockout of $H M M R$ would be needed to assess the effect of targeting RHAMM/HMMR in pancreatic cancer.

\section{Materials and Methods}

\section{Mouse Strains, Animal Husbandry, and Genotyping}

Cohorts of A, B, and $\mathrm{C}$ groups were of mixed genetic background. $p 48$-Cre; $L S L-K R A S^{G 12 D}$ mice were bred with $p 53^{\text {lox/lox }}$ mice and HMMR $R^{\text {Lexon8-16/4 exon8-16 }}$ mice (previously known as Rhamm$^{-/-}$ [23]). Cohorts of PNETs are generated by crossing RIP-Tag mice (C57BL/6 genetic background)

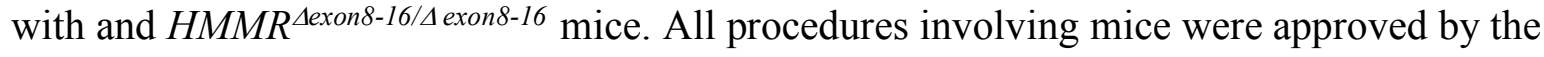
Institutional Animal Care and Use Committee. There was no noticeable influence of sex on the results of this study. This study was carried out in strict accordance with the recommendations in the Guide for the Care and Use of Laboratory Animals of the National Institutes of Health. All mice were housed in accordance with institutional guidelines.

Mouse genomic DNA was prepared for PCR genotyping through incubation of each earpiece in $200 \mu \mathrm{l} 0.05 \mathrm{M} \mathrm{NaOH}$ for 20 minutes at $98^{\circ} \mathrm{C}$ followed by the addition of $20 \mu \mathrm{l} 1 \mathrm{M}$ Tris- $\mathrm{HCl}$ $(\mathrm{pH} 7.5)$ at room temperature. Primers used in the PCR genotyping are as follows: for

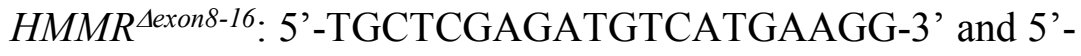
CGAGAGGTCCTTTTCACCAG-3' (a 360-bp product); for HMMR wild-type: 5'CCAGTGCCCGAGAGAATTTA-3' and 5'-TCCACTTGATCAGATGCACA-3' (a 338-bp product) or 5'-AGGGAGCAGTACAGAGGTGT-3' and 5'-TCGACAGCGTGTTCGGATAG-3' (a 535-bp product); for $L S L-K R A S^{G 12 D}$ : 5'-CGCAGACTGTAGAGCAGCG-3' and 5'- 
CCATGGCTTGAGTAAGTCTGC-3' (a 650-bp product); for p48-cre: 5'-

CTGATTTCGACCAGGTTCGT-3' and 5'-ATTCTCCCACCGTCAGTACG-3' (a 160-bp product); for p53 allele: 5'-GGTTAAACCCAGCTTGACCA-3' and 5'-

GGAGGCAGAGACAGTTGGAG-3' (a 370-bp product for $p 53^{\text {lox }}$, 240-bp product for WT). RIP-Tag PCR genotyping has been described [25].

\section{Sequencing of the $H M M R^{\Delta e x o n 8-16}$ Transcript and Western Blot Analysis}

Mouse testes were removed and frozen on dry ice immediately after euthanasia. The testes were crushed into powder form with liquid nitrogen, and RNA was purified from the powder using the RNeasy Plus Mini Kit (QIAGEN, \#74134). The purified RNA was used to synthesize cDNA using SuperScript ${ }^{\mathrm{TM}}$ IV VILO ${ }^{\mathrm{TM}}$ Master Mix with ezDNase ${ }^{\mathrm{TM}}$ Enzyme (Thermofisher, 11766050). An N-terminal HMMR fragment was amplified using AmpliTaq (Thermofisher, N8080153) or Q5 High-Fidelity DNA Polymerase (New England BioLabs, \#M0491L) with the following primer pairs: (1) 5'-AACCAGAGCCAACGAGCTAC-3' (on exon 5) and 5'AGCCTTGGAAGGGTCAAAGT-3' (on exon 17) (a 330 bp product to detect HMMR ${ }^{\text {4exon8-16 }}{ }^{\text {); }}$ and (2) 5'-CTCCGGGTGCTTATGATGTT-3' (on exon 2) and 5'-

CCGTTTTTCCAGTGAAGCAT-3' (on exon 5) (a 362-bp product for $H M M R^{\Delta e x o n 8-16}$ and WT to detect the missense mutation on exon 3). The resulting PCR products were purified using DNA Clean \& Concentrator (Zymo, D4013) and were sent to PSOMAGEN, INC. (formerly Macrogen Corp.) along with the primer, 5'-CCGTTTTTCCAGTGAAGCAT-3', for sequencing.

Frozen powders of mouse testes were lysed in NP-40 buffer (100 mM NaCl, $100 \mathrm{mM}$ Tris pH $8.2,0.5 \%$ NP-40) supplemented with a protease inhibitor mixture and PhosSTOP (Roche). 
Proteins were quantified by Bradford assay (Bio-Rad, Hercules, CA). Equal amounts of proteins were separated by SDS-PAGE and transferred to nitrocellulose membranes. To visualize equal protein loading, blots were stained with Ponceau S. Blots were incubated in 5\% non-fat milk in TBST, probed with primary antibodies to RHAMM (clone EPR4054, Abcam, ab124729, 1:500) or Cyclin B2 (R\&D, AF6204, $1 \mu \mathrm{g} / \mathrm{mL})$, and then incubated with horseradish peroxidase (HRP)conjugated secondary antibodies. Protein bands were visualized by enhanced chemical luminescence (Pierce, Rockford, IL).

\section{Immunohistochemistry}

Mouse tissues were fixed in $10 \%$ buffered formalin overnight at room temperature and then transferred to $70 \%$ ethanol, paraffin-embedded, and sectioned. Slides were deparaffinized and rehydrated by passaging through a graded xylene/ethanol series before staining.

Immunohistochemistry was performed using rabbit anti-RHAMM antibody (clone EPR4054, Abcam, ab124729, 1:500) as the primary antibody, followed by color development using the VECTASTAIN Elite ABC kit and counterstaining with hematoxylin.

\section{Statistical Analysis}

Mice from this study were monitored daily for signs of disease and mortality up to 1 year.

Kaplan-Meier method and log-rank test was used to test the survival differences between groups. Simulation method was used to adjust for multiple comparisons for log-rank test.

Publicly available gene expression (RNA-Seq version 2), harmonized mutations and gene level copy number datasets from The Cancer Genome Atlas (TCGA) were downloaded from the 
Genomic Data Commons Data Portal (https://portal.gdc.cancer.gov). Mann-Whitney U test and survival analysis were conducted for this dataset.

All analyses were performed in statistical software GraphPad Prism (version 7.0e) or SAS Version 9.4 (SAS Institute, Cary, NC). $P<0.05$ was considered statistically significant.

\section{Acknowledgements}

We thank Cornelia Tolg and Eva Ann Turley for providing Rhamm ${ }^{-/}$mice. We thank Danny Huang, Annie Yang, Makheni Jean-Pierre, Lei Tan, Shuibing Chen, Bing He, Mai Ho, Leticia

Dizon, Taotao Zhang, and Ruben Diaz for assistance. This work is partially supported by NIH R01CA204916-01A1, DoD W81XWH-16-1-0619, STARR I12-0043, and the Center for Translational Pathology at the Department of Pathology and Laboratory Medicine, Weill Cornell Medicine

\section{Competing Interests}

The authors declare no conflict of interest.

\section{References}

[1] R.L. Siegel, K.D. Miller, A. Jemal, Cancer statistics, 2018, CA Cancer J Clin, 68 (2018) 730.

[2] E. Pelosi, G. Castelli, U. Testa, Pancreatic Cancer: Molecular Characterization, Clonal Evolution and Cancer Stem Cells, Biomedicines, 5 (2017). 
[3] C.B. Westphalen, K.P. Olive, Genetically engineered mouse models of pancreatic cancer, Cancer J, 18 (2012) 502-510.

[4] S.R. Hingorani, E.F. Petricoin, A. Maitra, V. Rajapakse, C. King, M.A. Jacobetz, S. Ross, T.P. Conrads, T.D. Veenstra, B.A. Hitt, Y. Kawaguchi, D. Johann, L.A. Liotta, H.C. Crawford, M.E. Putt, T. Jacks, C.V. Wright, R.H. Hruban, A.M. Lowy, D.A. Tuveson, Preinvasive and invasive ductal pancreatic cancer and its early detection in the mouse, Cancer Cell, 4 (2003) 437450.

[5] N. Bardeesy, A.J. Aguirre, G.C. Chu, K.H. Cheng, L.V. Lopez, A.F. Hezel, B. Feng, C. Brennan, R. Weissleder, U. Mahmood, D. Hanahan, M.S. Redston, L. Chin, R.A. Depinho, Both p16(Ink4a) and the p19(Arf)-p53 pathway constrain progression of pancreatic adenocarcinoma in the mouse, Proc Natl Acad Sci U S A, 103 (2006) 5947-5952.

[6] A. Dasari, C. Shen, D. Halperin, B. Zhao, S. Zhou, Y. Xu, T. Shih, J.C. Yao, Trends in the Incidence, Prevalence, and Survival Outcomes in Patients With Neuroendocrine Tumors in the United States, JAMA Oncol, 3 (2017) 1335-1342.

[7] J.L. Buicko, B.M. Finnerty, T. Zhang, B.J. Kim, T.J. Fahey, 3rd, Y.C. Nancy Du, Insights into the biology and treatment strategies of pancreatic neuroendocrine tumors, Ann Pancreat Cancer, 2 (2019).

[8] T. Zhang, S. Choi, T. Zhang, Z. Chen, Y. Chi, S. Huang, J.Z. Xiang, Y.N. Du, miR-431 Promotes Metastasis of Pancreatic Neuroendocrine Tumors by Targeting DAB2 Interacting Protein, a Ras GTPase Activating Protein Tumor Suppressor, Am J Pathol, 190 (2020) 689-701.

[9] I.P. Michael, S. Saghafinia, D. Hanahan, A set of microRNAs coordinately controls tumorigenesis, invasion, and metastasis, Proc Natl Acad Sci U S A, (2019). 
[10] D. Hanahan, Heritable formation of pancreatic beta-cell tumours in transgenic mice expressing recombinant insulin/simian virus 40 oncogenes, Nature, 315 (1985) 115-122.

[11] G. Bergers, S. Song, N. Meyer-Morse, E. Bergsland, D. Hanahan, Benefits of targeting both pericytes and endothelial cells in the tumor vasculature with kinase inhibitors, J Clin Invest, 111 (2003) 1287-1295.

[12] M. Paez-Ribes, E. Allen, J. Hudock, T. Takeda, H. Okuyama, F. Vinals, M. Inoue, G. Bergers, D. Hanahan, O. Casanovas, Antiangiogenic therapy elicits malignant progression of tumors to increased local invasion and distant metastasis, Cancer Cell, 15 (2009) 220-231. [13] K. Pietras, D. Hanahan, A multitargeted, metronomic, and maximum-tolerated dose "chemo-switch" regimen is antiangiogenic, producing objective responses and survival benefit in a mouse model of cancer, J Clin Oncol, 23 (2005) 939-952.

[14] S.M. Yao JC, Ito T, Bohas CL, Wolin EM, Van Cutsem E, Hobday TJ, Okusaka T, Capdevila J, de Vries EG, Tomassetti P, Pavel ME, Hoosen S, Haas T, Lincy J, Lebwohl D, Öberg K, Everolimus for advanced pancreatic neuroendocrine tumors, N Engl J Med, 364 (2011) 514-523.

[15] C.P. Blumenthal GM, Zhang JJ, Tang S, Sridhara R, Murgo A, Justice R, Pazdur R, FDA approval summary: Sunitinib for the treatment of progressive well-differentiated locally advanced or metastatic pancreatic neuroendocrine tumors, Oncologist, 17 (2012) 1108-1113. [16] E.A. Turley, Purification of a hyaluronate-binding protein fraction that modifies cell social behavior, Biochem Biophys Res Commun, 108 (1982) 1016-1024.

[17] Y.T. Chen, Z. Chen, Y.N. Du, Immunohistochemical analysis of RHAMM expression in normal and neoplastic human tissues: a cell cycle protein with distinctive expression in mitotic cells and testicular germ cells, Oncotarget, 9 (2018) 20941-20952. 
[18] S. Sohr, K. Engeland, RHAMM is differentially expressed in the cell cycle and downregulated by the tumor suppressor p53, Cell Cycle, 7 (2008) 3448-3460.

[19] C. Hardwick, K. Hoare, R. Owens, H.P. Hohn, M. Hook, D. Moore, V. Cripps, L. Austen, D.M. Nance, E.A. Turley, Molecular cloning of a novel hyaluronan receptor that mediates tumor cell motility, J Cell Biol, 117 (1992) 1343-1350.

[20] D. Wang, N. Narula, S. Azzopardi, R.S. Smith, A. Nasar, N.K. Altorki, V. Mittal, R. Somwar, B.M. Stiles, Y.N. Du, Expression of the receptor for hyaluronic acid mediated motility (RHAMM) is associated with poor prognosis and metastasis in non-small cell lung carcinoma, Oncotarget, (2016).

[21] S. Choi, D. Wang, X. Chen, L.H. Tang, A. Verma, Z. Chen, B.J. Kim, L. Selesner, K. Robzyk, G. Zhang, S. Pang, T. Han, C.S. Chan, T.J. Fahey, 3rd, O. Elemento, Y.N. Du, Function and clinical relevance of RHAMM isoforms in pancreatic tumor progression, Mol Cancer, 18 (2019) 92.

[22] Y.C. Du, C.K. Chou, D.S. Klimstra, H. Varmus, Receptor for hyaluronan-mediated motility isoform B promotes liver metastasis in a mouse model of multistep tumorigenesis and a tail vein assay for metastasis, Proc Natl Acad Sci U S A, 108 (2011) 16753-16758.

[23] C. Tolg, R. Poon, R. Fodde, E.A. Turley, B.A. Alman, Genetic deletion of receptor for hyaluronan-mediated motility (Rhamm) attenuates the formation of aggressive fibromatosis (desmoid tumor), Oncogene, 22 (2003) 6873-6882.

[24] S.R. Hingorani, L. Wang, A.S. Multani, C. Combs, T.B. Deramaudt, R.H. Hruban, A.K. Rustgi, S. Chang, D.A. Tuveson, Trp53R172H and KrasG12D cooperate to promote chromosomal instability and widely metastatic pancreatic ductal adenocarcinoma in mice, Cancer Cell, 7 (2005) 469-483. 
[25] G. Zhang, Y. Chi, Y.N. Du, Identification and Characterization of Metastatic Factors by Gene Transfer into the Novel RIP-Tag; RIP-tva Murine Model, J Vis Exp, (2017).

[26] C.A. Maxwell, J. McCarthy, E. Turley, Cell-surface and mitotic-spindle RHAMM:

moonlighting or dual oncogenic functions?, Journal of cell science, 121 (2008) 925-932.

[27] N. Schatz-Siemers, Y.T. Chen, Z. Chen, D. Wang, L.H. Ellenson, Y.N. Du, Expression of the Receptor for Hyaluronic Acid-Mediated Motility (RHAMM) in Endometrial Cancer is Associated With Adverse Histologic Parameters and Tumor Progression, Appl Immunohistochem Mol Morphol, 28 (2020) 453-459.

[28] L. Song, M. Rape, Regulated degradation of spindle assembly factors by the anaphasepromoting complex, Mol Cell, 38 (2010) 369-382.

[29] V. Joukov, A.C. Groen, T. Prokhorova, R. Gerson, E. White, A. Rodriguez, J.C. Walter, D.M. Livingston, The BRCA1/BARD1 heterodimer modulates ran-dependent mitotic spindle assembly, Cell, 127 (2006) 539-552.

[30] M.A. Pujana, J.-D.J. Han, L.M. Starita, K.N. Stevens, M. Tewari, J.S. Ahn, G. Rennert, V. Moreno, T. Kirchhoff, B. Gold, V. Assmann, W.M. Elshamy, J.-F. Rual, D. Levine, L.S. Rozek, R.S. Gelman, K.C. Gunsalus, R.A. Greenberg, B. Sobhian, N. Bertin, K. Venkatesan, N. AyiviGuedehoussou, X. Solé, P. Hernández, C. Lázaro, K.L. Nathanson, B.L. Weber, M.E. Cusick, D.E. Hill, K. Offit, D.M. Livingston, S.B. Gruber, J.D. Parvin, M. Vidal, Network modeling links breast cancer susceptibility and centrosome dysfunction, Nat Genet, 39 (2007) 1338-1349. [31] H. Li, L. Frappart, J. Moll, A. Winkler, T. Kroll, J. Hamann, I. Kufferath, M. Groth, S. Taudien, M. Schutte, M.L. Yaspo, H. Heuer, B.M. Lange, M. Platzer, K. Zatloukal, P. Herrlich, A. Ploubidou, Impaired Planar Germ Cell Division in the Testis, Caused by Dissociation of 
RHAMM from the Spindle, Results in Hypofertility and Seminoma, Cancer Res, 76 (2016) 6382-6395.

[32] M. Connell, H. Chen, J. Jiang, C.W. Kuan, A. Fotovati, T.L. Chu, Z. He, T.C. Lengyell, H. Li, T. Kroll, A.M. Li, D. Goldowitz, L. Frappart, A. Ploubidou, M.S. Patel, L.M. Pilarski, E.M. Simpson, P.F. Lange, D.W. Allan, C.A. Maxwell, HMMR acts in the PLK1-dependent spindle positioning pathway and supports neural development, eLife, 6 (2017).

[33] H. Li, J. Moll, A. Winkler, L. Frappart, S. Brunet, J. Hamann, T. Kroll, M.H. Verlhac, H. Heuer, P. Herrlich, A. Ploubidou, RHAMM deficiency disrupts folliculogenesis resulting in female hypofertility, Biol Open, 4 (2015) 562-571. 
Table 1. Histological Phenotypes and Average Life Span of Mice

\begin{tabular}{|c|c|c|c|}
\hline Group & Genotype & Histology & $\begin{array}{c}\text { Median } \\
\text { survival (week) }\end{array}$ \\
\hline A0 & p48-Cre; LSL-KRAS GI2D & PanIN & 46.79 \\
\hline A1 & $p 48-C r e ; L S L-K R A S^{G 12 D} ; H M M R^{\operatorname{Lexon8-16/WT}}$ & PanIN & undefined \\
\hline A2 & p48-Cre; LSL-KRAS GI2D;HMMR & PanIN & 48.86 \\
\hline B0 & p48-Cre; LSL-KRAS $S^{G I 2 D} ; p 53^{l o x /+}$ & PDAC & 23.93 \\
\hline B1 & p48-Cre; LSL-KRAS $S^{G 12 D} ; p 53^{\text {lox/+}} ; H M M R^{\Delta e x o n 8-16 / W T}$ & PDAC & 17.50 \\
\hline B2 & p48-Cre $; L S L-K R A S^{G 12 D} ; p 53^{l o x /+} ; H M M R^{\operatorname{sexon} 8-16 / \Delta \text { exons-16 }}$ & PDAC & 15.41 \\
\hline $\mathrm{C} 0$ & p48-Cre; LSL-KRAS $S^{G I 2 D} ; p 53^{\text {lox/lox }}$ & PDAC & 9.14 \\
\hline $\mathrm{C} 1$ & p48-Cre; LSL-KRAS ${ }^{G 12 D} ; p 53^{\text {lox/lox }} ; H M M R^{\text {dexon8-16/WT }}$ & PDAC & 9.86 \\
\hline $\mathrm{C} 2$ & p48-Cre; LSL-KRAS G12D; $553^{\text {lox/lox }} ; H M M R^{\operatorname{Lexon} 8-16 / \Delta \text { exon8-16 }}$ & PDAC & 9.57 \\
\hline T0 & RIP-Tag & PNET & 17.57 \\
\hline $\mathrm{T} 1$ & 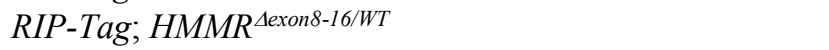 & PNET & 16.14 \\
\hline $\mathrm{T} 2$ & RIP-Tag; HMMR ${ }^{\text {Lexon8-16/4 exon8-16 }}$ & PNET & 15.50 \\
\hline
\end{tabular}




\section{Figure Legends}

\section{Figure 1. Comparison of WT mouse RHAMM/HMMR protein and HMMR ${ }^{\Delta e x o n 8-16}$. (A)}

Deduced amino acid sequence of HMMR $\mathrm{H}^{\Delta \text { exon8-16 }}$ and WT mouse RHAMM/HMMR (translated from NM_013552.2). Potential hyaluronan-binding sites (BX7B motif) are shown in shaded boxes. Sequences from exon 4 are indicated by an orange line. A missense mutation from lysine (K) to threonine (T) at residue 71 is shown in red font. (B) Western blot analysis of mouse

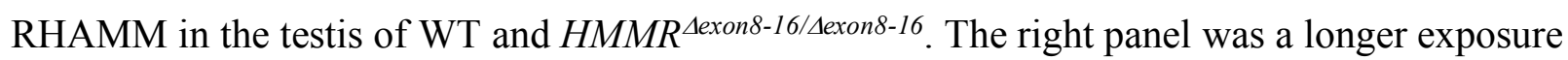
than the left panel for RHAMM. Cyclin B2 was used as a control. (C) Immunohistochemical staining showed RHAMM staining in the germ cells of testis from a $H M M R^{\text {\exon8-16/4exon8-16 }}$ mouse, at stronger intensity than that observed in the testis of a WT mouse. Original magnification, 200X.

Figure 2. A missense mutation at nucleotide position 290 of the coding region of $H M M R^{\Delta e x o n 8-16}$. (A) DNA sequencing showed a mutation from T to G (antisense strand) from HMMR transcripts in the testis of a $H M M R^{\Delta e x o n 8-16 / 4 \text { exon8-16 }}$ mouse, as compared to transcripts derived from the testis of a WT mouse. (B) Sequence alignment between a partial fragment of $H M M R^{4 e x o n 8-16}$ and a partial coding sequence of NM_013552.2 showed an A to C missense mutation at nucleotide position 290 .

Figure 3. HMMR ${ }^{\Delta e x o n 8-16 / \Delta e x o n 8-16}$ mice have normal pancreas and $H M M R^{\Delta e x o n 8-16}$ does not significantly change the survival of $p 48-C r e$; $L S L-K R A S^{G 12 D}$ mice. (A-D) Hematoxylin and eosin (H\&E) stain of representative pancreas from (A) $H M M R^{\text {4exon8-16/4exon8-16 }}$ mouse, (B) A0: p48-Cre; LSL-KRAS G12D mouse, (C) A1: p48-Cre; LSL-KRAS ${ }^{G 12 D} ; H M M R^{4 e x o n 8-16 / W T}$ mouse, (D) 


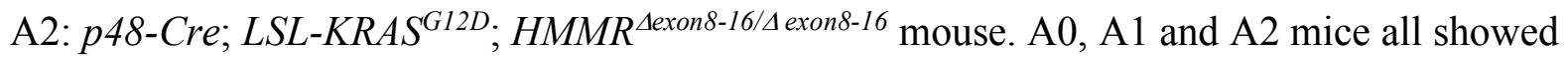
localized ductal proliferation consistent with PanINs, but no evidence of invasive PDAC. (E) Kaplan-Meier survival curve for A0, A1, and A2 mice. Tukey adjusted $P$ values from pairwise log-rank test were shown. Original magnification, 200X.

Figure 4. HMMR ${ }^{4 e x o n 8-16}$ shortened the survival of $p 48-C r e ; L S L-K R A S^{G 12 D} ; p 53^{l o x / 4}$ mice.

(A) Kaplan-Meier survival curve for B0, B1, and B2 mice. Tukey adjusted $P$ values from pairwise log-rank test were shown. (B-E) H\&E stain of invasive PDAC from (B) a 22-week-old B0: p48-Cre; LSL-KRAS $S^{G 12 D} ;$ p53 $3^{\text {lox/+ }}$ mouse, (C) a 25.9-week-old B0: p48-Cre; LSL-KRAS G12D; $p 53^{\text {lox/+ }}$ mouse, (D) a 19.7-week-old B1: p48-Cre; LSL-KRAS ${ }^{G 12 D} ;$ p53 lox/+$; H M M R^{\text {Lexon8-16/WT }}$ mouse, and (E) a 18.9-week-old B1: p48-Cre; LSL-KRAS G12D; $p 53^{\text {lox/+}} ; H M M R^{\text {Lexon8-16/WT }}$ mouse. (F) H\&E stain of a peripancreatic lymph node (LN) invaded by PDAC from the same animal in (D). (G) H\&E stain of liver metastasis of PDAC from a 14.9-week-old B2: p48-Cre; LSL-

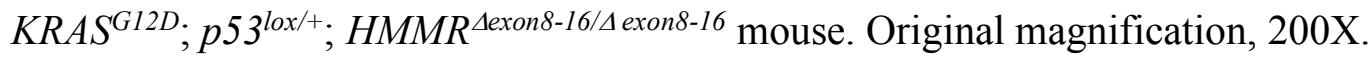

Figure 5. HMMR $R^{\Delta e x o n 8-16}$ accelerated PDAC formation in p48-Cre; $L S L-K R A S^{G 12 D}$; p53 $3^{l o x /+}$

mice. $H \& E$ stain of representative PDAC from B group mice at 15 weeks of age. (A and B) two B0: p48-Cre; LSL-KRAS $S^{G 12 D} ;$ p53 $3^{l o x /+}$ mice. (C and D) two B1: p48-Cre; LSL-KRAS G12D; $p 53^{\text {lox/+ }}$;

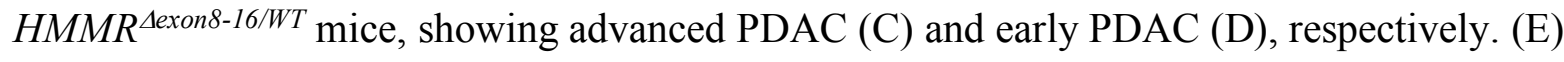
H\&E stain of a peripancreatic lymph node (LN) invaded by PDAC from the same animal in (C). Original magnification, 200X. 
Figure 6. The $p 48-C r e ; L S L-K R A S^{G 12 D} ; p 53^{l o x / l o x}$ mice had too rapid PDAC progression to potentiate the effect of $\boldsymbol{H M M R ^ { \Delta e x o n 8 - 1 6 }}$. (A-C) H\&E stain of representative PDAC from (A) a 9week-old C0: p48-Cre; LSL-KRAS ${ }^{G 12 D} ;$ p53 lox/lox mouse, (B) an 8-week-old C1: p48-Cre; LSL-

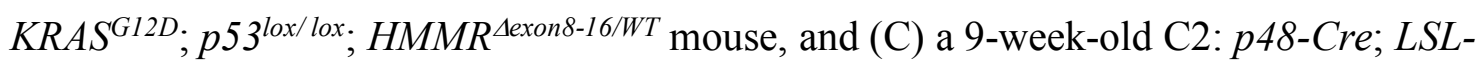

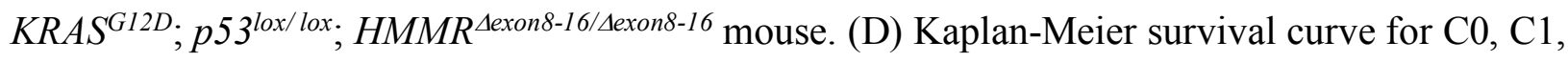
and C2 mice. Tukey adjusted $P$ values from pairwise log-rank test were shown. Original magnification, 200X.

Figure 7. HMMR ${ }^{\Delta e x o n 8-16}$ reduced the survival of RIP-Tag PNET mice. H\&E stain of representative PNETs from (A) a 15-week-old T0: RIP-Tag mouse, (B) a 15-week-old T1: RIP-

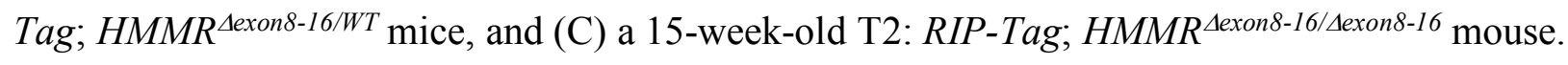
(D) Kaplan-Meier survival curve for T0, T1, and T2 mice. Tukey adjusted $P$ values from pairwise log-rank test were shown. Original magnification, 200X.

Figure 8. The association between TP53 mutational status/copy number loss and RHAMM/HMMR expression levels in TCGA pancreatic cancer dataset. (A) Upregulation of RHAMM/HMMR expression in the TCGA pancreatic cancer patients with TP53 mutations. WT: wild type $(\mathrm{n}=53)$; MU: mutation $(\mathrm{n}=66)$. (B) Upregulation of $R H A M M / H M M R$ expression in the patients with copy number loss $(\mathrm{CN}=1, \mathrm{n}=49)$ compared to autosomal copy number $(\mathrm{CN}=2$, $\mathrm{n}=59)$. (C) Combination of TP53 mutations and high $R H A M M / H M M R$ expression predicted worse outcome. (D) Combination of TP53 copy number loss $(\mathrm{CN}=1)$ and high $R H A M M / H M M R$ expression predicted worse outcome. High (H) and low (L) was based on the 75 quartile RHAMM/HMMR expression value. $P$ values from log-rank test were shown in $\mathrm{C}$ and $\mathrm{D}$. 

bioRxiv preprint doi: https://doi.org/10.1101/2021.02.19.432042; this version posted February 20, 2021. The copyright holder for this preprint
(which was not certified by peer review) is the author/funder. All rights reserved. No reuse allowed without permission.

A
$\Delta$ exon8-16
MSFPKAPLKRFNDPSGCAPSPGAYDVKTSEATKGPVSFOKSORFKNQRESQQNLNIDKDT
60
60
Aexon8-16 TLLASAKKAKTSVSKKDSQKNDKDVKRLEKEIRALLQERGTQDKRIQDMESELEKTEAKL
WT TLLASAKKAKKSVSKKDSOKNDKDVKRLEKEIRALLQERGTODKRIODMESELEKTEAKL
120
$\star * * * * * * * * * * * * * * * * * * * * * * * * * * * * * * * * * * * * * * * * * * * * * * * * * * * * * * * * * *$
$\Delta$ exon8-16
NAAVREKTSLSASNASLEKRLTELTRANELLKAKFSEDGHQKNMRALSLELMKLRNKRET
NAAVREKTSLSASNASLEKRLTELTRANELLKAKFSEDGHOKNMRALSLELMKLRNKRET

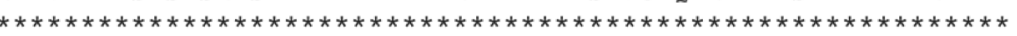
Sexon8-16 KMRSMMVKQEGMELKLQATQKDLTESKGKIVQLEGKLRCONSDLSLLK------------G
WT KMRSMMVKQEGMELKLQATQKDLTESKGKIVQLEGKLVSIEKEK IDEKCETEKLLEY IQE
229
$\star * * * * * * * * * * * * * * * * * * * * * * * * * * * * * * * * * * * *$. : . :
$\Delta$ exon8-16
NKMSSDFREN-
WT
ISCASDQVEKCKVDIAQLEEDLKEKDRE ILSLKOSLEENITF SKOIEDLTVKCOLLETER
. $* * *$ :
$\Delta$ exon8-16
WT
DNLVSKDRERAETLSAEMQILTERLALERQEYEKLQQKELQSQSLLQQEKELSARLQQQ
239
$\Delta$ exon8-16
WT
CSFQEEMTSEKNVFKEELKLALAELDAVQQKEEQSERLVKQLEEETKSTAEQLTRLDNLL
239
420
$\Delta$ exon8-16
REKEVELEKHIAAHAQAILIAQEKYNDTAQSLRDVTAQLESVQEKYNDTAQSLRDVTAQL
239
WT
$\Delta$ exon $8-16$
WT
ESEQEKYNDTAQSLRDVTAQLESEQEKYNDTAQSLRDVTAQLESVQEKYNDTAQSLRDVT
239
$\Delta$ exon8-16
WT
AQLESYKSSTLKEIEDLKLENLTLQEKVAMAEKSVEDVQQQILTAESTNQEYARMVQDLQ
239
$\Delta$ exon8-16
NRSTLKEEEIKEITSSFLEKITDLKNQLRQQDEDFRKQLEEKGKRTAEKENVMTELTMEI
239
660
$\Delta$ exon $8-16$
WT
NKWRLLYEELYEKTKPFQQOLDAFEAEKOALLNEHGATQEOLNK IRDSYAQLLGHONLKO
239
720
$\Delta$ exon8-16
WT

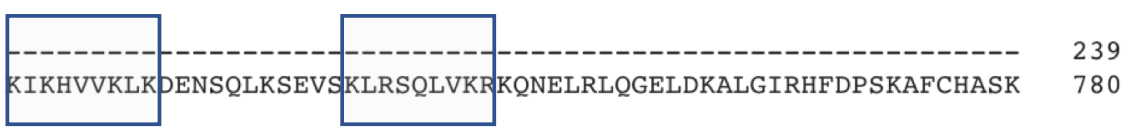
$\Delta$ exon8-16
WT
ENFTPLKEGNPNCC 794

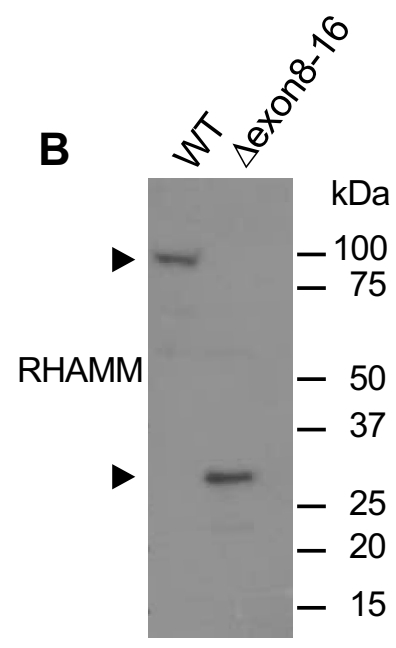

Cyclin B2

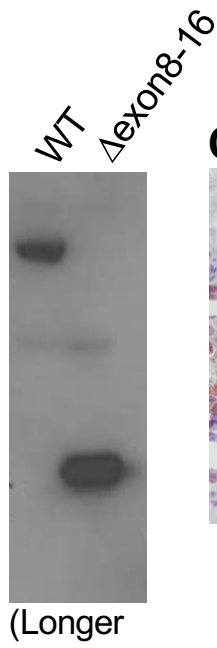

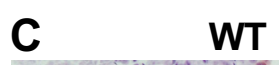
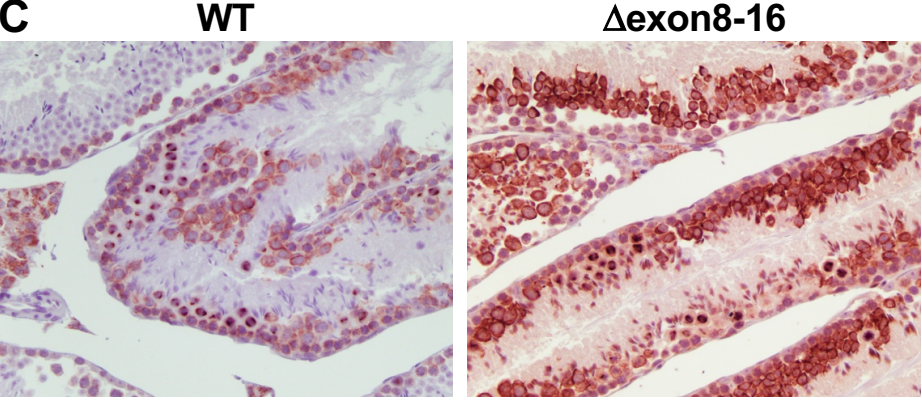
bioRxiv preprint doi: https://doi.org/10.1101/2021.02.19.432042; this version posted February 20, 2021. The copyright holder for this preprint (which was not certified by peer review) is the author/funder. All rights reserved. No reuse allowed without permission.

A

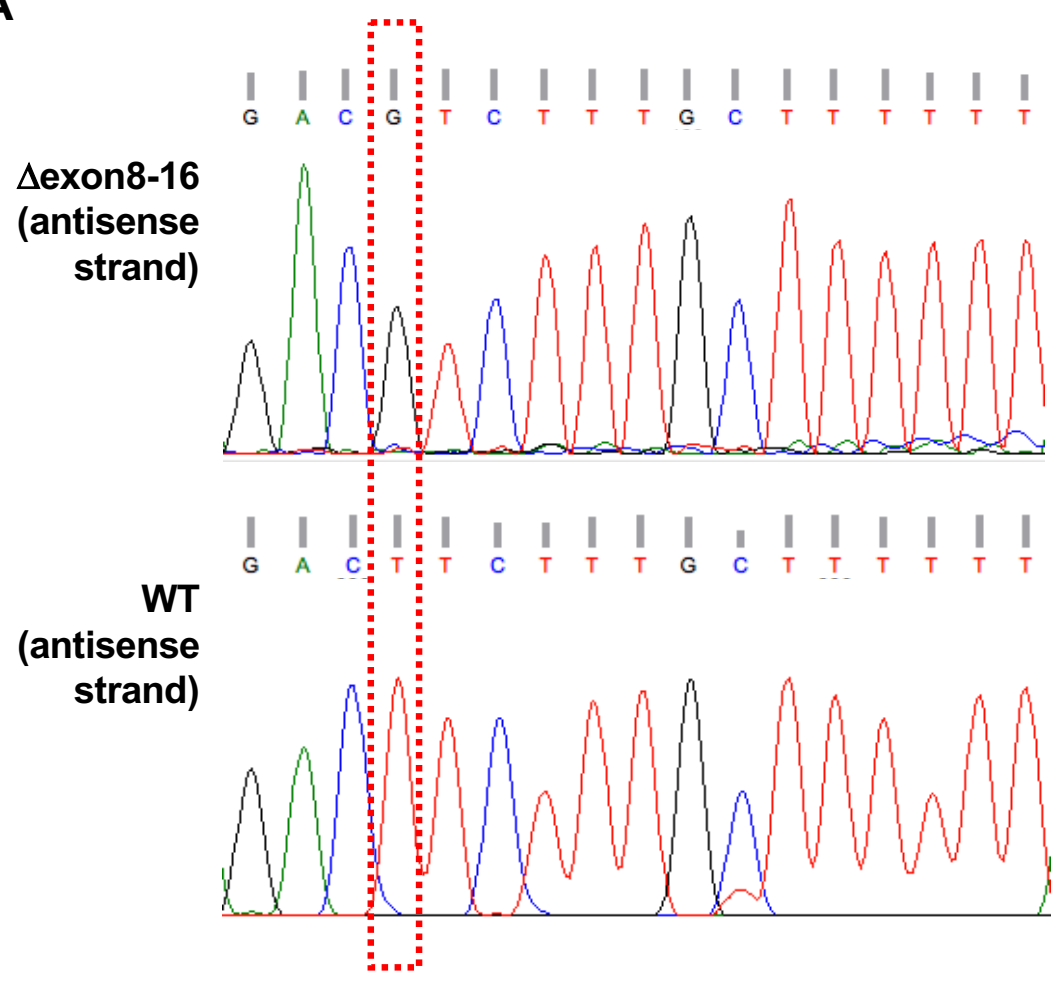

B

$\Delta$ exon8-16

WT

$\Delta$ exon8-16

WT

$\Delta$ exon8-16

พT

$\Delta$ exon8-16

WT

$\Delta$ exon8-16

WT

$\Delta$ exon8-16

WT

$\Delta$ exon8-16

WT

$\Delta$ exon8-16

WT

$\Delta$ exon8-16

WT

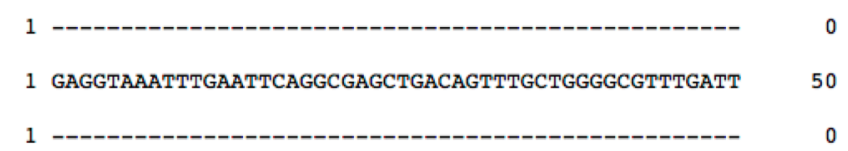

51 GCTGTCTCATCTGGACCCAGGCGTCAGAATGTCCTTTCCTAAGGCGCCCC 100

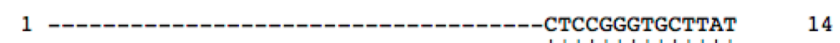

| || || || || |||

101 TGAAGAGATTCAATGACCCTTCGGGTTGTGCTCCATCTCCGGGTGCTTAT 150

15 GATGTTAAAACTTCAGAagCAACTAAAgGaCCAgtGTCTTTTCAGAAAC 64 | | | | | | | | | | | | | | | | | | | | | | | | | | | | | | | | | | | | | | | | | | | | | | | | | | | | | 20

65 ACAAAGATTTAAAAACCAAAGAGAGTCTCAACAAAATCTTAACATTGACA 114 |||||||||||||||||||||||||||||||||||||||||||||||||| 201 ACAAAGATTTAAAAACCAAAGAGAGTCTCAACAAAATCTTAACATTGACA 250

115 AAgATACAACCTTGCTTGCTTCGGCTAAAAAAGCAAAG:GTCTGTGTCA 164 || |||||||||||||||||||||||||||||||||||||||| |.||||||||||| 251 AAGATACAACCTTGCTTGCTTCGGCTAAAAAAGCAAAGATGTCTGTGTCA 300

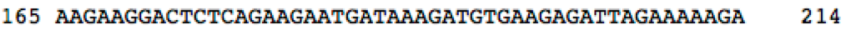
|||||||||||||||||||||||||||||||||||||||||||||||||| 301 AAGAAGGACTCTCAGAAGAATGATAAAGATGTGAAGAGATTAGAAAAAGA 350

215 GATTCGCGCTCTTTTGCAAGAGCGAGGGACTCAGGACAAACGGATCCAGG ||||||||||||||||||||||||||||||||||||||||||||||||||||| 351 GATTCGCGCTCTTTTGCAAGAGCGAGGGACTCAGGACAAACGGATCCAGG 400

265 ACATGGAATCTGAATTGGAGAAGACAGAAGCAAAGCTCAATGCAGCAGTC 314 |||||||||||||||||||||||||||||||||||||||||||||||||| 401 ACATGGAATCTGAATTGGAGAAGACAGAAGCAAAGCTCAATGCAGCAGTC 450 

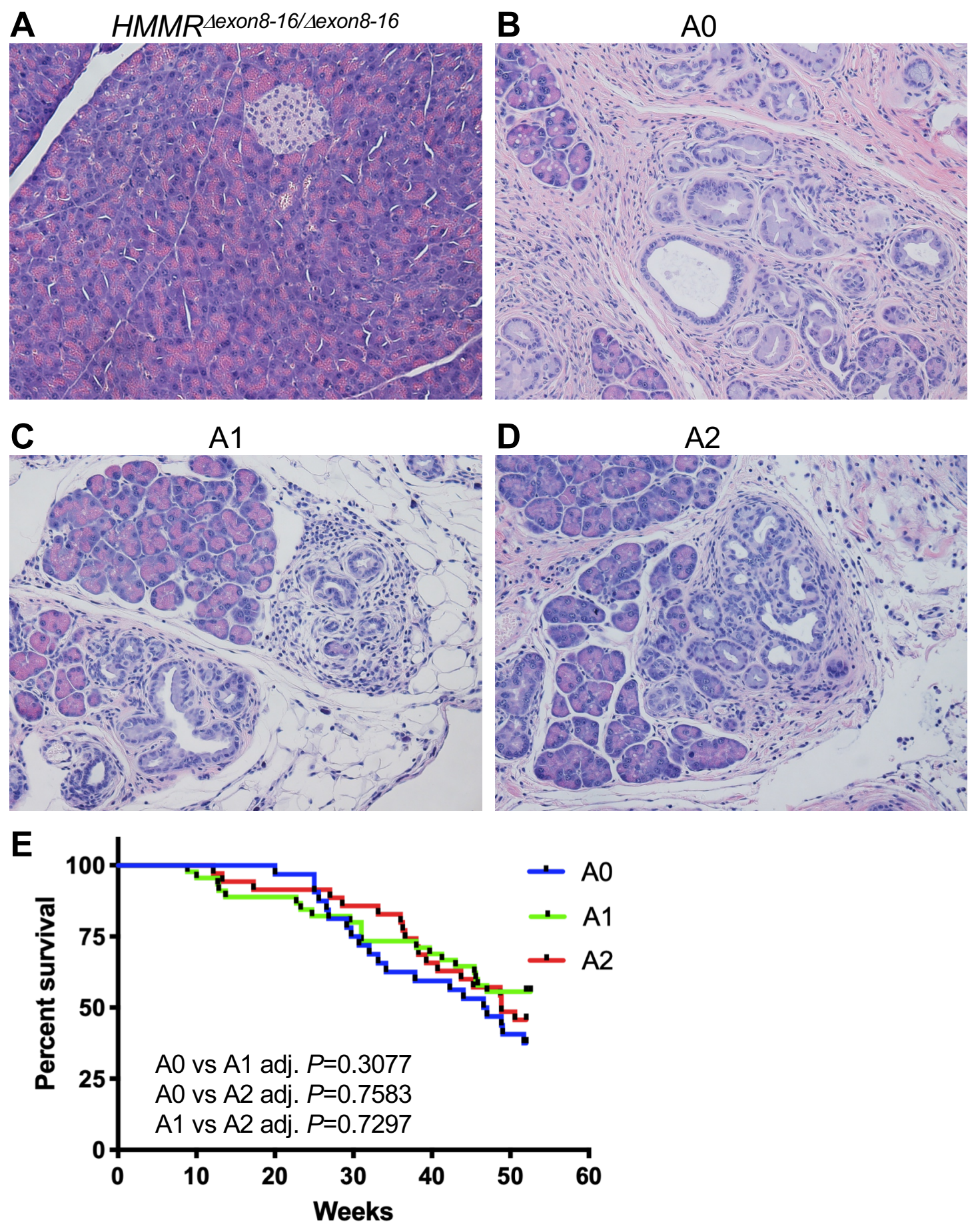


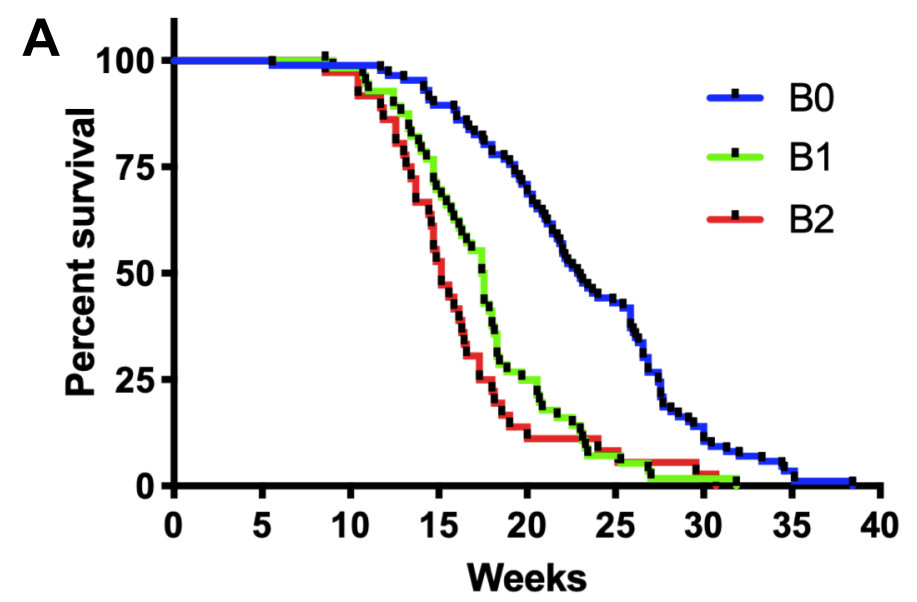

B0 vs $B 1$ adj. $P<0.0001$

$B 0$ vs $B 2$ adj. $P<0.0001$

$B 1$ vs $B 2$ adj. $P=0.9627$

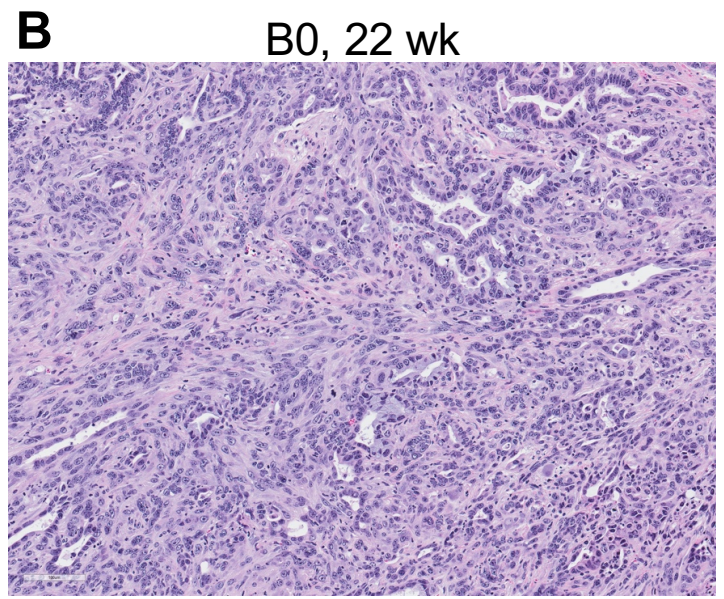

C BO, 25.9wk

D

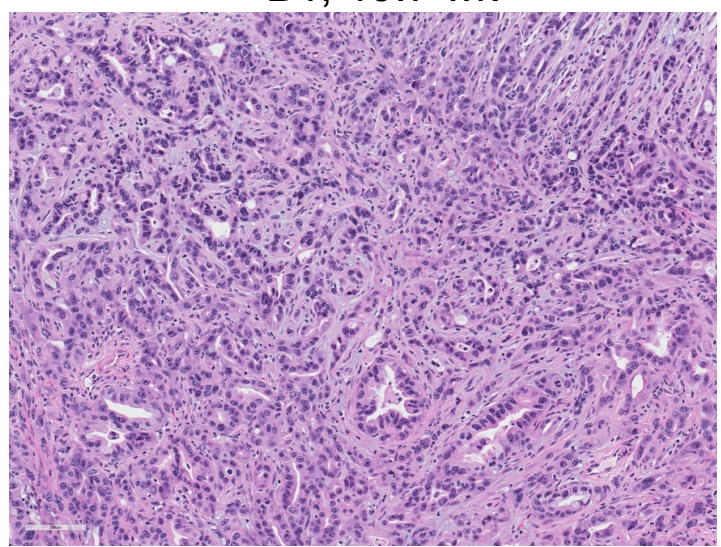

F $\quad$ B1, $19.7 w k$, invasive to LN

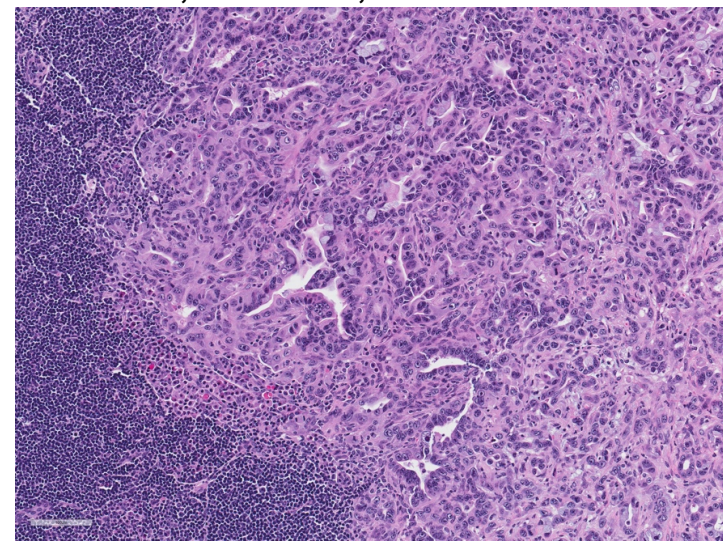

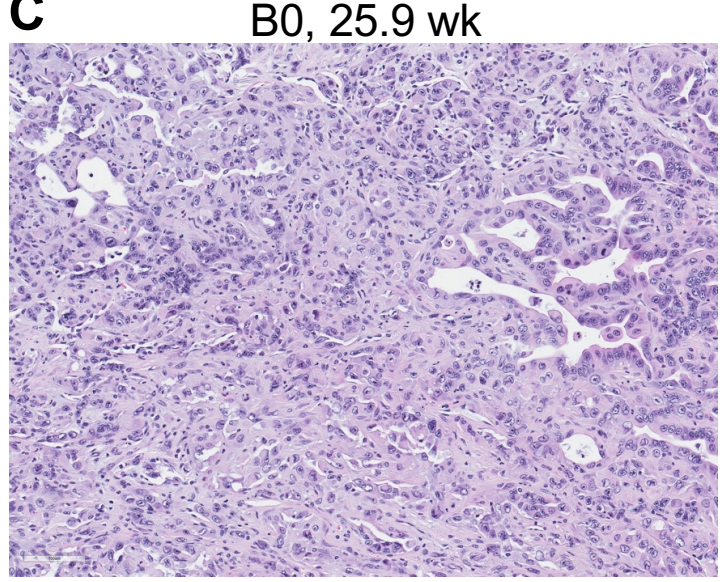
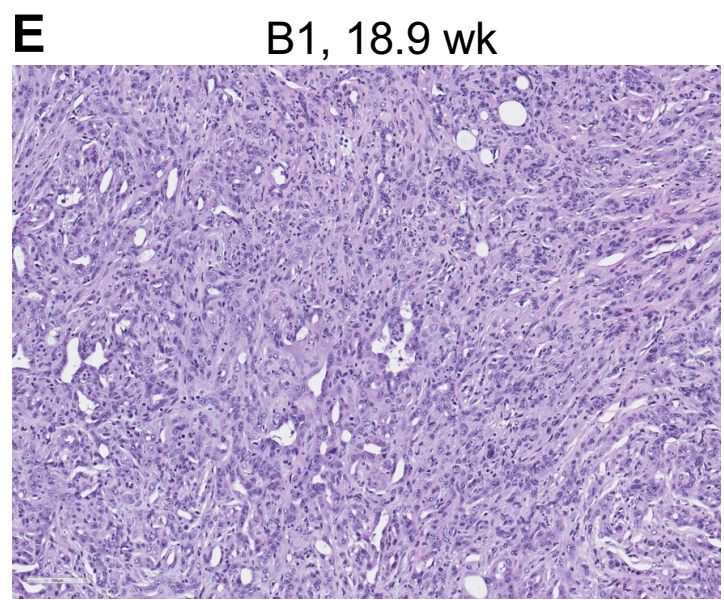

\section{G B2, 14.9 wk, liver mets}

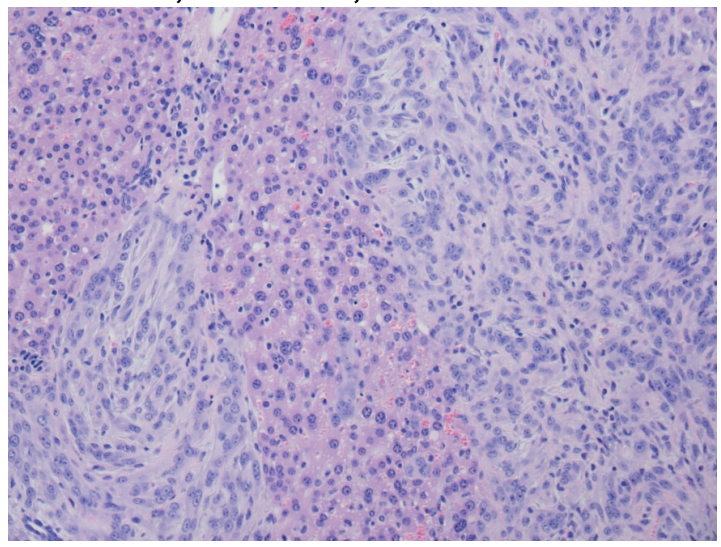


A

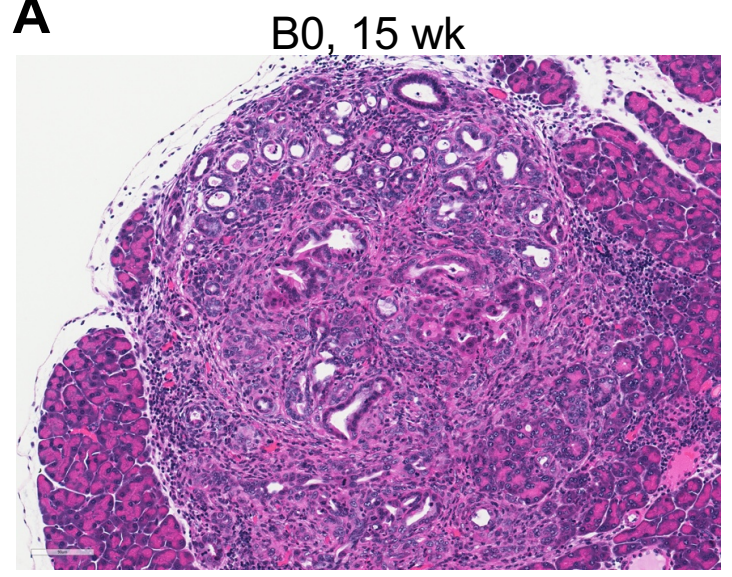

C

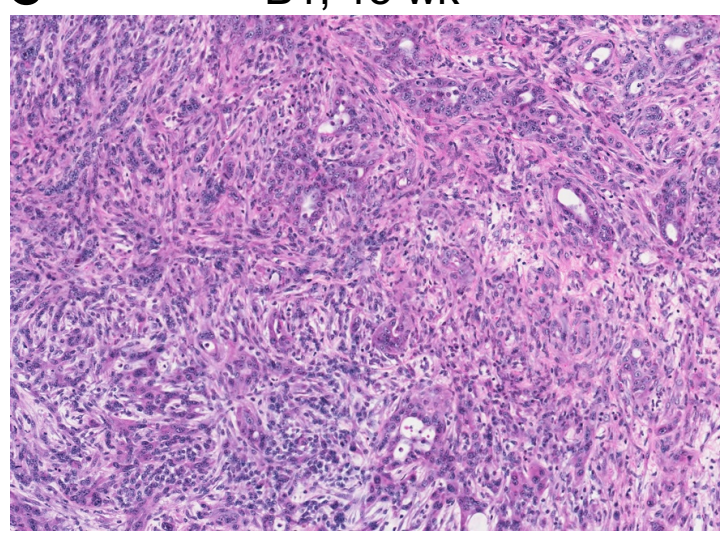

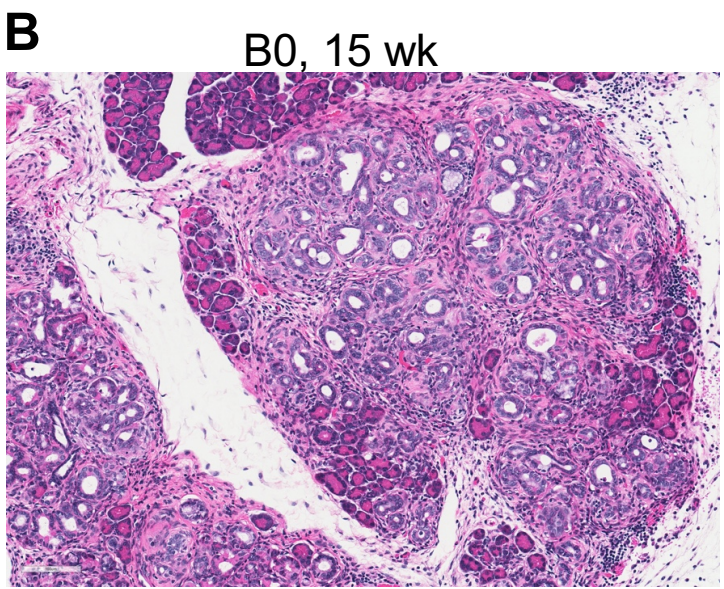

D $\quad$ B1, $15 w k$

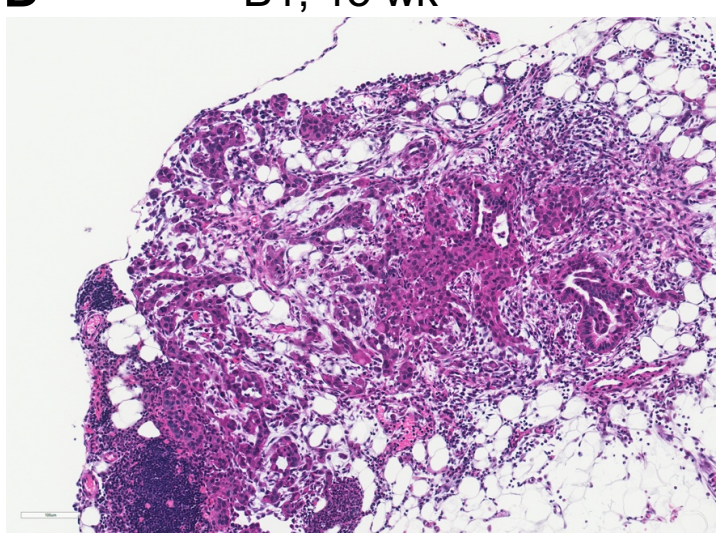

\section{E B1, 15 wk, invasive to LN}

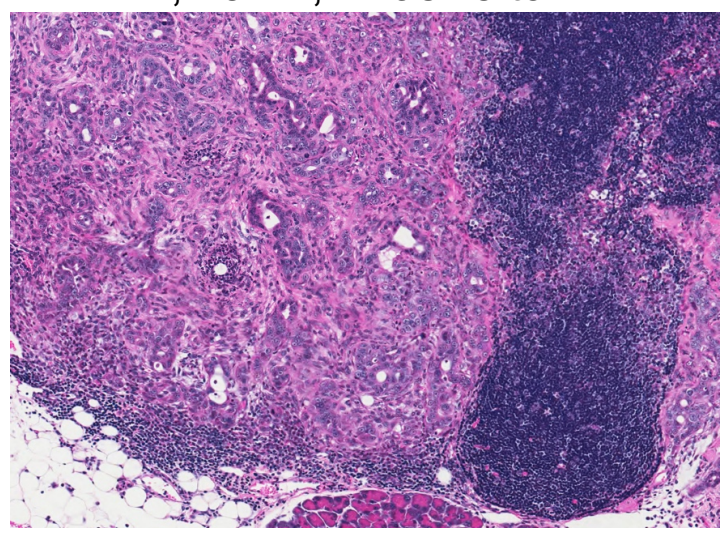


A

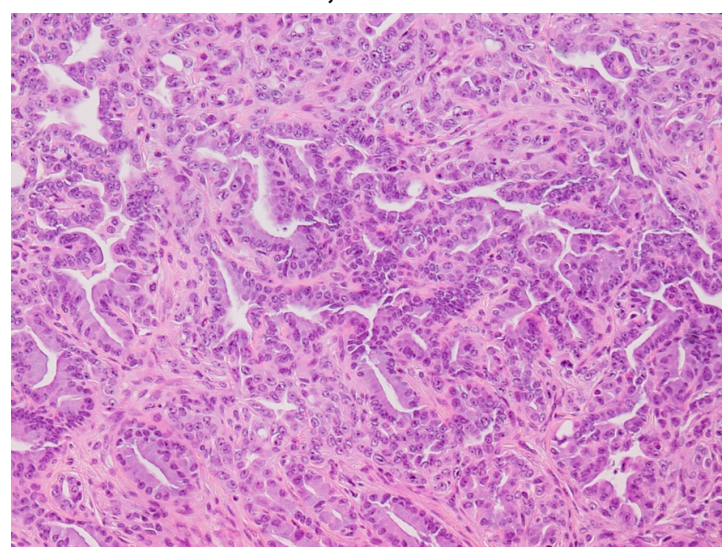

\section{C}

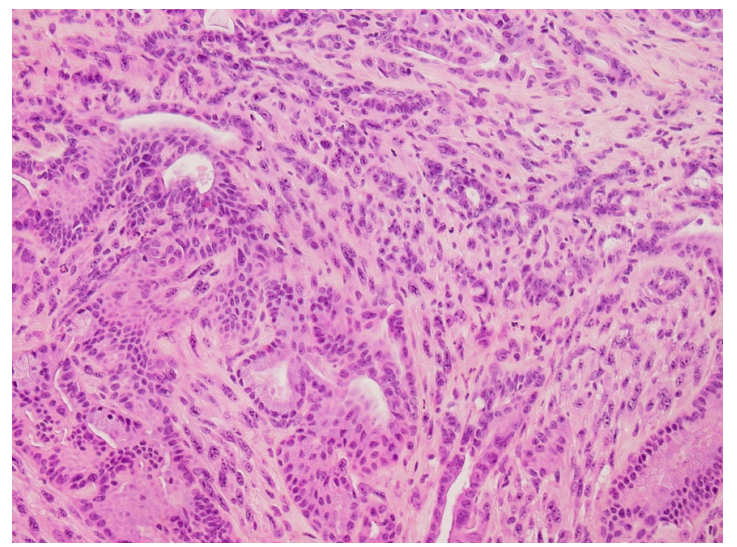

B

C1, 8 wk

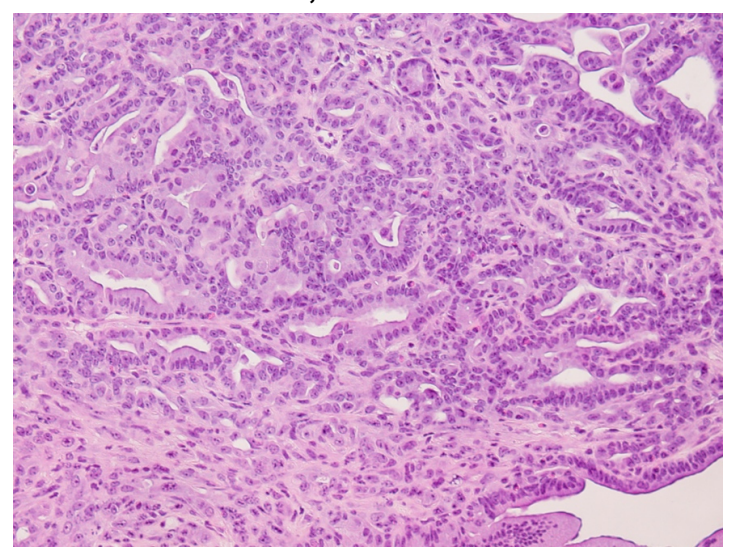

D

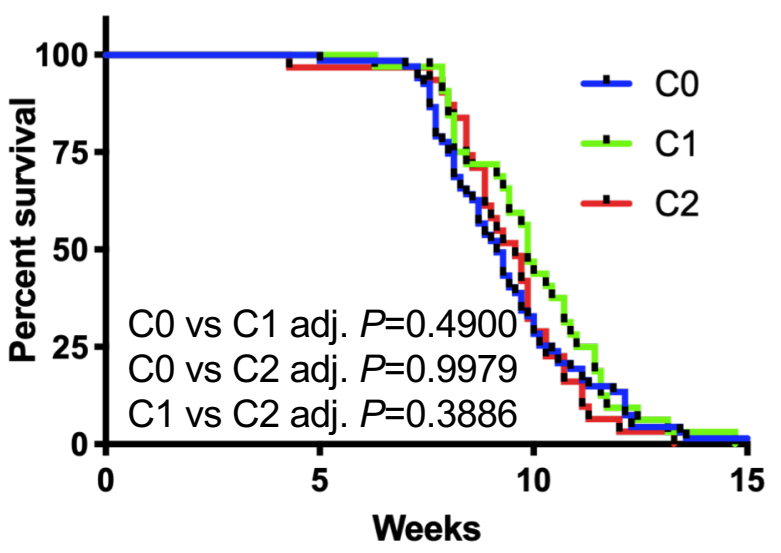



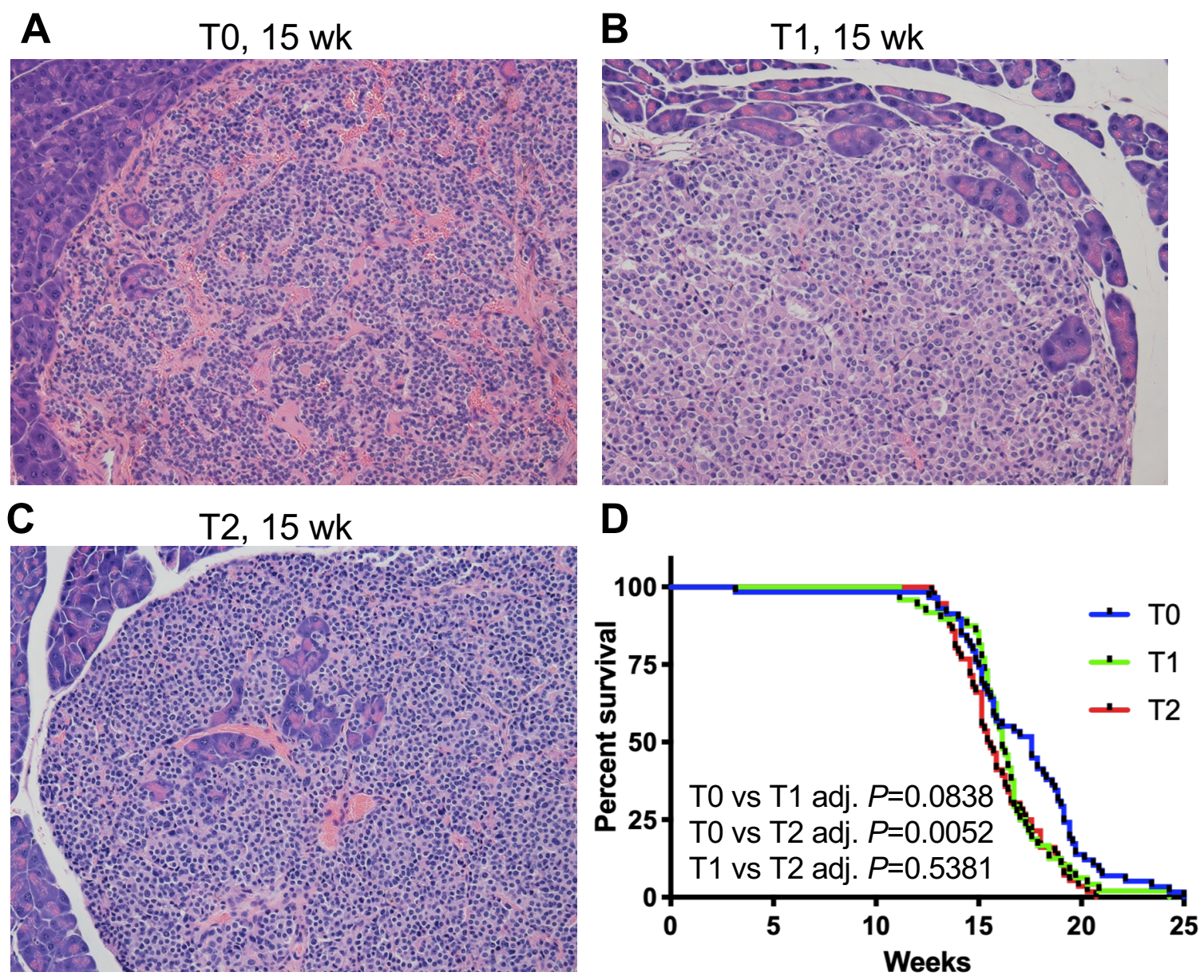
A

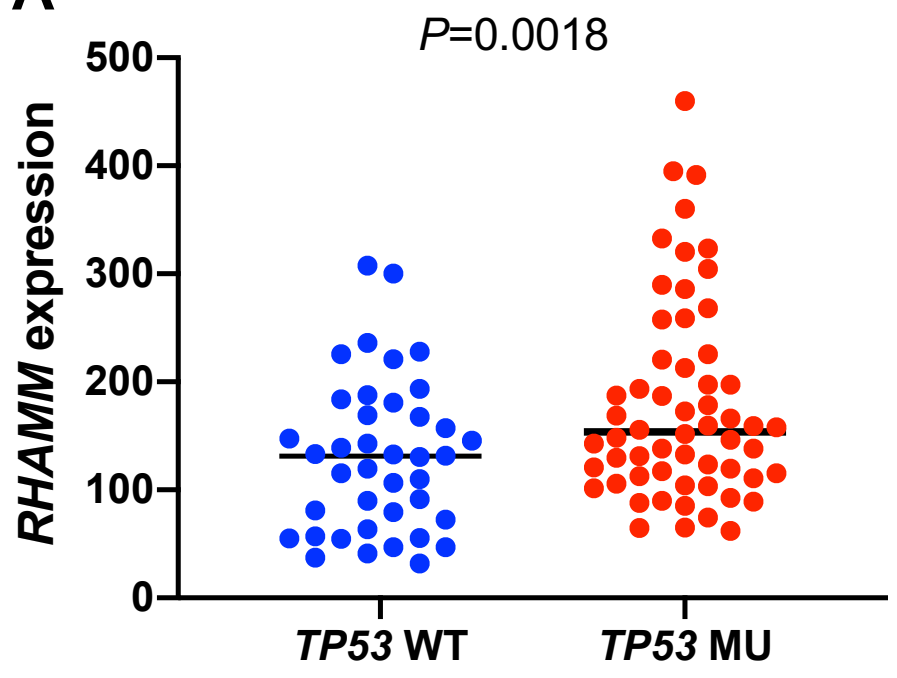

C

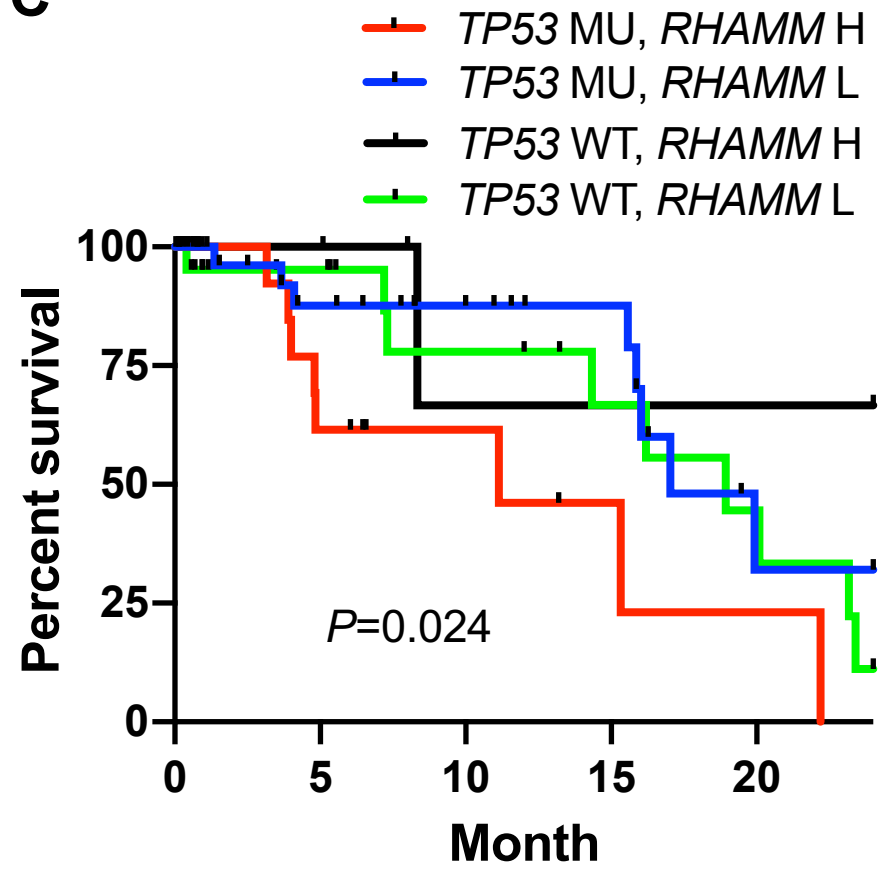

B

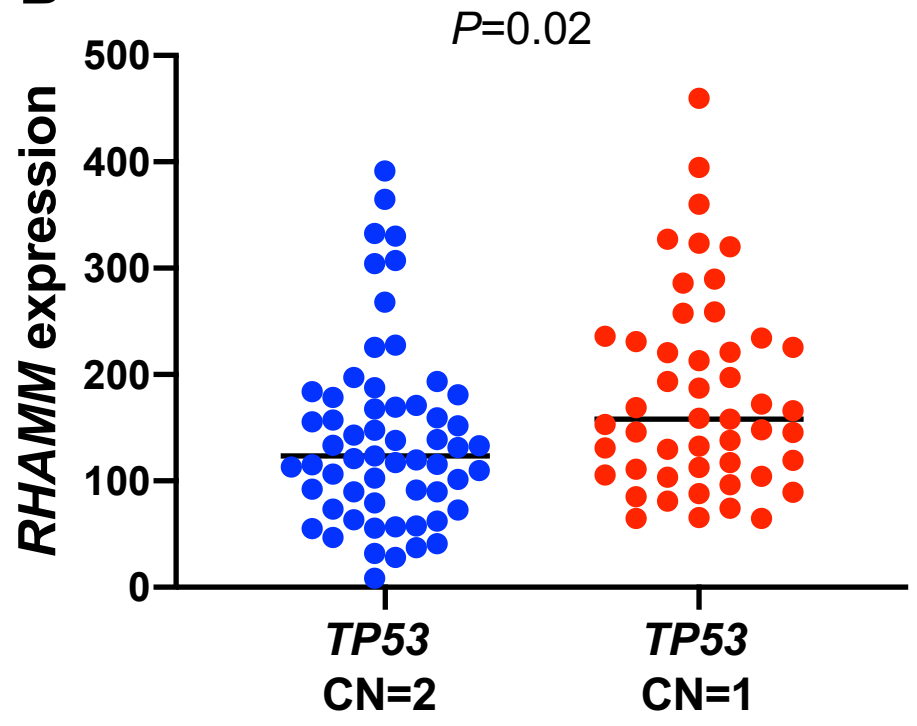

D

- TP53 CN=1, RHAMM H

- TP53 CN=1, RHAMM L

- TP53 $\mathrm{CN}=2, \mathrm{RHAMM} \mathrm{H}$

- TP53 CN=2, RHAMM L

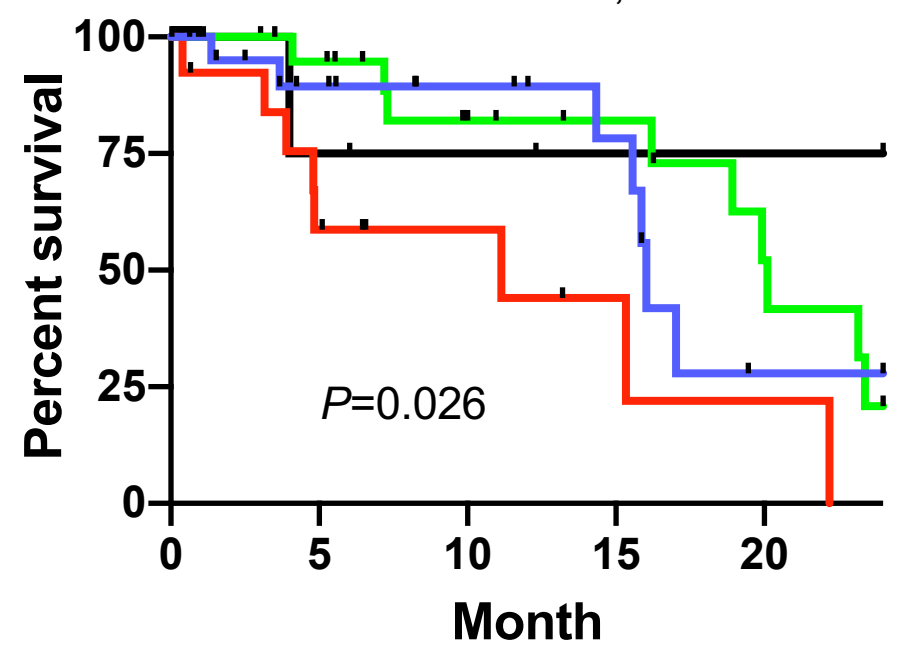

